Article

\title{
Aerosol Optical Properties and Direct Radiative Effects over Central China
}

\author{
Ming Zhang ${ }^{1,+}$, Lunche Wang ${ }^{2, *}+{ }^{+}$, , Wei Gong ${ }^{1,3, *}$, Yingying Ma ${ }^{1,3}$ and Boming Liu ${ }^{1}$ \\ 1 State Key Laboratory of Information Engineering in Surveying, Mapping and Remote Sensing, \\ Wuhan University, Wuhan 430079, China; mingzhang@whu.edu.cn (M.Z.); yingyingma_aer@126.com (Y.M.); \\ zgm61@163.com (B.L.) \\ 2 Laboratory of Critical Zone Evolution, School of Earth Sciences, China University of Geosciences, \\ Wuhan 430074, China \\ 3 Collaborative Innovation Center for Geospatial Technology, Wuhan 430079, China \\ * Correspondence: wang@cug.edu.cn (L.W.); weigong_whu@163.com (W.G.); \\ Tel.: +86-133-4988-9828 (L.W.); +86-135-1724-1678 (W.G.) \\ + These authors contributed equally to this work.
}

Received: 9 August 2017; Accepted: 21 September 2017; Published: 26 September 2017

\begin{abstract}
Central China is important for aerosols and climate because it is among the worst regions for air pollution in China. However, it is understudied due to a lag in establishing an atmospheric monitoring network. So we did a comprehensive analysis using multiple techniques to improve the understanding of aerosol optical properties and their radiative effect in this region. The results showed that high aerosol optical depth (AOD) was generally found in the northern and central parts, whereas low values were observed in the southern and western parts. Most regions were predominantly loaded with small aerosol particles and a significant influence of long-distance transported dust was found in springtime. A strong and significantly decreasing trend was observed with a maximum decrease rate of -0.08 per year in the northern and western parts, related to the decreasing emission of aerosols and increasing rainfall. Aerosol optical properties and radiative effects were compared between an urban site, Wuhan, and a rural site, Dengfeng. The seasonal variations of AOD and Ångström exponent (AE) are similar for Wuhan and Dengfeng, but both values are larger in Wuhan than in Dengfeng. A greater dominance of coarse-mode and absorbing aerosols was found over Dengfeng. Annual averaged aerosol radiative effect (ARE) in shortwave spectrum $\left(A R E_{S W}\right)$ and its efficiency (REE) are $-48.01 \mathrm{~W} / \mathrm{m}^{2}$ and $-51.38 \mathrm{~W} / \mathrm{m}^{2}$, respectively, in Wuhan, $-40.02 \mathrm{~W} / \mathrm{m}^{2}$ and $-53.26 \mathrm{~W} / \mathrm{m}^{2}$, respectively, in Dengfeng. The dependence of REE on aerosol absorptive and size properties was studied; the results showed that REE was strongly influenced by the aerosol absorptivity and size of fine-mode particles, but there was not a strong correlation between REE and AE. The percentage of ARE in visible spectrum (AREVIS) in $A R E_{S W}$ in Wuhan was $3 \%$ lower than in Dengfeng. The ARE $E_{V I S}$ percentage depended largely on aerosol particle size, but was less influenced by aerosol absorptivity.
\end{abstract}

Keywords: aerosols; radiative effect; source region analysis

\section{Introduction}

Aerosols of natural and anthropogenic origins contribute substantially to global climate change [1,2]. Apart from their crucial role in air pollution, such as haze and dust storms, aerosols influence the climate directly by scattering and absorbing the incoming solar radiation and indirectly by altering cloud microphysical properties [3]. Aerosols can also influence the circulation features and heat transport [4], and have an impact on precipitation rates and the hydrological 
cycle [5,6] - for example, absorbing aerosols may be partly responsible for the increasing floods in southern China and drought in northern China in the past decades [5,7].

Assessing aerosol effects on a climate system depends significantly on aerosol properties. The direct radiative effects of aerosols are governed by aerosol optical properties, which depend on particle composition and size [8]. Indirect effects of aerosol are also related to aerosol properties such as particle type, size, and concentration [9-11]. However, aerosols are extremely short-lived in the atmosphere (lifetime on the order of a week) $[12,13]$ and their sources, emissions, and removal mechanisms are very complex. Aerosols exist in various shapes, sizes, and structures; the composition of aerosols is dynamic and transforms as particles coagulate and absorb water [12,14]. As a result, the spatial distribution and temporal variations of aerosol are highly inhomogeneous; the complicated aerosol properties further cause much uncertainty in the estimation of climate change $[15,16]$. Thus, a thorough, region-oriented understanding of aerosol properties and their spatial and temporal distribution is necessary before the aerosol effects on the climate system can be evaluated accurately $[17,18]$.

To obtain aerosol properties and reduce uncertainty in estimating aerosol effects on the climate system, great efforts have been exerted to improve the aerosol observations [19-21]. Aerosol properties can be obtained through laboratory measurements, but such measurements can only characterize aerosols on the surface, and some sampling methods may change the natural status of ambient aerosol [22]. Satellite remote sensing measurements can provide information about the global distribution and dynamics of aerosol optical depth (AOD) and also an estimate of aerosol particle size. However, satellite observation cannot provide complete aerosol optical parameters for quantification of aerosol absorptive or scattering properties at present, although they are essential for assessing the direct radiative effects on the earth's surface and the top of the atmosphere [23]. Ground-based remote sensing observations are generally characterized by high precision and temporal resolution but low spatial and temporal coverage. Ground-based measurements can provide relatively accurate inversions for aerosol optical and microphysical parameters, such as aerosol size distribution (ASD) and single scattering albedo (SSA). The integrated use of satellite and ground-based observations can provide a comprehensive understanding of the optical and microphysical properties of aerosols. Moreover, data from collocated instruments can reveal underlying aerosol-governing physics [24].

Based on the aerosol optical and microphysical properties derived from ground and satellite observations, the direct aerosol radiative effect (ARE) can be estimated to evaluate the scattering and absorption effect of aerosol on solar radiation. Most studies on ARE in the shortwave spectrum (SW) have focused on the entire SW spectrum or a certain spectral interval in the SW spectrum, such as visible (VIS) and ultraviolet (UV) spectra $[25,26]$. Studies on ARE have found cooling effects of aerosols on the Earth's surface in the SW spectrum [27,28]. However, knowledge of ARE on the surface in each spectral interval of the SW spectrum is still lacking. The seasonal variations of ARE in the UV, VIS, and near-infrared (NIR) intervals and their fractions in SW as well as the mechanism governing ARE variation need further investigation.

Due to the complicated properties and inhomogeneous distributions of aerosol, region-oriented studies of aerosol properties and ARE have been conducted, especially in dust-affected regions such as the Middle East and heavily polluted areas such as the Yangtze River Delta in China [26,29]. However, central China is relatively understudied compared to the coastal areas due to a lag in establishing an atmospheric monitoring network. It is important to study this area because it is a key transportation hub and among the most economically developed areas in China.

Central China is located between $24^{\circ} \mathrm{N}$ and $37^{\circ} \mathrm{N}$ latitude and $108^{\circ} \mathrm{E}$ and $117^{\circ} \mathrm{E}$ longitude (Figure 1), which covers the middle reach of the Yangtze River and the middle and lower reaches of the Yellow River. Fast-growing anthropogenic activities and an economic boom have resulted in increasing aerosol loading in this region, thereby causing serious air pollution and frequent haze [30] and making this area one of the most heavily populated regions in China. Limited knowledge is available on the radiative effect and spatial distribution of aerosol loading in this region, and studies on aerosol properties 
focus on vast regions of countryside, mountains, and forests. Furthermore, information is lacking on the long-term variation trend of aerosol properties as a result of the short duration of ground-based observation. The serious air pollution in central China has drawn attention and some measures such as forbidding straw combustion and installing desulfurization and denitration equipment in thermal power plants have been conducted in the past few years. The question of whether air pollution has been suppressed requires an investigation of long-term, region-wide aerosol trends.

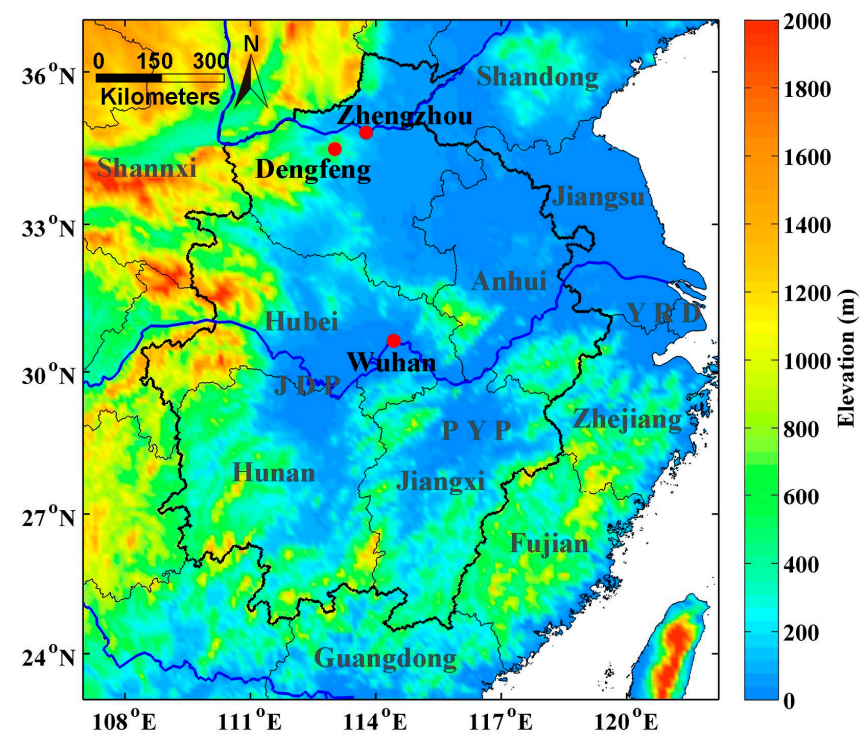

Figure 1. Elevation map of study area. JDP, PYP, and YRD represent the Jianghan and Dongting Plain, Poyang Plain, and Yangtze River Delta, respectively.

This study analyzes the aerosol spatial distribution and trends over Central China using the Collection 6 data of MODIS (Moderate Resolution Imaging Spectroradiometer) based on the refined retrieved algorithms [31]. Sun-photometric observations from an urban area in Wuhan and a rural site in Dengfeng have also been used to investigate the complete aerosol optical and microphysical properties, such as SSA and ASD, as well as aerosol radiative effects on the surface. Sun-photometric measurements have been collected in these two locations for four years, allowing for a statistically meaningful analysis of aerosol properties. Then, these aerosol properties were used as input in a radiative transfer model to simulate solar irradiance and calculate the corresponding ARE. Instead of generally analyzing ARE in the entire SW spectrum, we elaborated the investigation of ARE and its efficiency in UV, VIS, NIR, and SW solar radiation spectra on the surface. The detailed analysis of aerosol properties significantly improves the development of aerosol models over central China, and also extends their applicability, for example, in modeling aerosol impacts on climate and improving atmospheric radiative transfer models by providing more accurate parameters. The rest of this paper is organized as follows. Section 2 describes the satellite-based and ground-based data and analytical methods; the spatial distribution and seasonal variation of aerosol optical and microphysical properties and potential sources of pollutants during the haze period in central China are discussed in Section 3; sensitivity of ARE to uncertainties in aerosol optical properties are analyzed in Section 4.

\section{Materials and Methods}

\subsection{Data}

\subsubsection{Satellite Data}

The satellite measurements of aerosol properties are taken from Terra satellite's MODIS sensor, which has been in operation since February 2000. The MODIS instrument observes the upwelling 
radiation at the top of the atmosphere in 36 channels from 0.41 to $4.00 \mu \mathrm{m}$, which is characterized by high spatial-temporal resolution. Aerosol properties are retrieved using well-calibrated spectral bands. The latest version (Collection 006) of MODIS, which is derived by refined retrieval algorithms, provides extended spatiotemporal coverage, which is important in investigating the aerosol properties over regions with high surface albedo and complex topography in central China [31].

\subsubsection{Ground-Based Measurements}

The ground-based aerosol properties were derived from direct solar irradiance and sky radiance measured by Cimel sun-photometers deployed in the Wuhan and Dengfeng sites. Direct sun measurements are generally performed every $15 \mathrm{~min}$ (more frequently at sunrise and sunset), and sky radiances are measured every hour [32]. The instruments measure direct spectral solar radiation in eight channels of 340, 380, 440,500,675, 870, 940, and $1020 \mathrm{~nm}$. Measurements of direct spectral solar radiation at $940 \mathrm{~nm}$ were used to derive total precipitable water vapor (PWV) while measurements from other channels were used to obtain the spectral AOD $[33,34]$. The estimated uncertainty is 0.01-0.02 for AOD (larger at shorter wavelengths) [20]. The Ångström exponent (AE) $\alpha$ was obtained from AOD inversions at 440 and $870 \mathrm{~nm}$, and the Ångström turbidity $\beta$ was calculated from the AE value and AOD at $1020 \mathrm{~nm}$. The sun-photometer can also measure sky irradiance at 440, 675, 870, and $1020 \mathrm{~nm}$, which were used to derive aerosol properties such as ASD, SSA, and asymmetry factor (AF) combined with direct radiation observations following the flexible inversion algorithm developed by Dubovik and King [34] and Dubovik et al. [35]. The uncertainty of SSA is between 0.05 and 0.07 for $\mathrm{AOD}<0.2$, and is 0.03 for $\mathrm{AOD}>0.2$ [35], while the uncertainty in the retrieval of AF lies in the 3-5\% range [36].

\subsection{Methods}

\subsubsection{LibRadtran Model Description}

The libRadtran model [37] is a library of radiative transfer routines and programs; it includes a selection of different radiative transfer equation solvers such as a fast two-stream code [38], a discrete ordinated method code (DISORT) by Stamnes et al. [39], and its improved version (DISORT2) [40]. The libRadtran model structures the atmosphere as multilayers, considering the vertical profiles of pressure, temperature, and atmospheric components, such as aerosols and gases [37].

\subsubsection{ARE Calculations}

The retrieved aerosol parameters from sun-photometric observations were used as input in the libRadtran model to calculate the fluxes and ARE on the surface in ultraviolet (ARE $E_{U V}$, 280-400 nm), visible (ARE $\mathrm{VIS}, 400-700 \mathrm{~nm}$ ), near-infrared (ARE $\mathrm{NIR}, 700-2800 \mathrm{~nm}$ ), and shortwave $\left(\mathrm{ARE}_{\mathrm{SW}}, 280-2800 \mathrm{~nm}\right)$ spectra under cloud-free conditions. The other input parameters include Level-3 daily ozone $\left(\mathrm{O}_{3}\right)$ data obtained from the Ozone Monitoring Instrument (OMI) and the surface albedo at $440,675,870$, and $1020 \mathrm{~nm}$ derived by using the AERONET algorithm, which depends on the Li-Ross model and uses the bidirectional reflectance distributions derived from MODIS observations [41,42]. The irradiances in the UV, VIS, and NIR spectral regions were calculated by the DISORT2 solver. The spectral irradiance in the UV spectrum was calculated by using the SSA, AF, and surface albedo at $440 \mathrm{~nm}$. The same parameters at $675 \mathrm{~nm}$ were used in the VIS region, and the averaged values at 870 and $1020 \mathrm{~nm}$ were used in the NIR range. In each spectral interval, the aerosol properties were considered to be wavelength-independent. The irradiance in the SW spectrum was calculated by adding up the irradiance in the three spectral intervals.

The instantaneous ARE $\left(A R E_{\text {ins }}\right)$ values in each spectral interval were obtained by calculating the difference between the irradiance with and without aerosols as follows:

$$
A R E_{\text {ins }}=F_{\text {aer }}^{\text {net }}-F_{\text {clean }}^{\text {net }}
$$


where $F_{a e r}^{\text {net }}$ is the total net irradiance on the surface that suffered an external perturbation due to aerosols and $F_{\text {clean }}^{\text {net }}$ corresponds to the total atmospheric net irradiance at the same level that did not suffer the perturbation from aerosols. We first calculated $A R E_{i n s}$ in 10-min intervals. To compute the daily averaged ARE, we postulate that aerosol concentration remains relatively constant during the entire day and interpolate aerosol optical properties across periods of cloud present and missing data (including nighttime) to create a continuous time series. The daily averaged $A R E\left(A R E_{d a y}\right)$ was then calculated by the integration of the instantaneous data during the whole day ( $24 \mathrm{~h}$ ), considering $A R E_{\text {ins }}=0 \mathrm{~W} / \mathrm{m}^{2}$ for solar zenith angle larger than $90^{\circ}[43,44]$ :

$$
A R E_{\text {day }}=\frac{\sum_{0}^{24} A R E_{i n s} d t}{24 h} .
$$

To make a consistent comparison among aerosol radiative effects, aerosol radiative effect efficiency (REE) was calculated as the rate at which the atmosphere is forced per unit of AOD at $440 \mathrm{~nm}$. To ensure data quality and representativeness, only observations larger than 5 times per day were selected for daily average calculation and daily observation larger than 10 times in each month were used to conduct monthly mean calculation, which is consistent with data screening criterion in the work of Wang et al. [30]. A total of 529 days (29 months) and 387 days (21 months) passed data screening and were used for Wuhan and Dengfeng, respectively.

\subsubsection{Back Trajectories}

Three-day backward trajectories on an hourly scale at $500 \mathrm{~m}$ above the ground level for main cities in central China were generated by the Hybrid Single-Particle Lagrangian Integrated Trajectory (HYSPLIT) model of the National Oceanic and Atmospheric Administration (NOAA). The trajectories were then clustered to study the possible impact of local and transported sources on the formation of haze in central China.

The concentration weighted trajectory (CWT) algorithm was implemented to localize major sources of $\mathrm{PM}_{2.5}$ (particulate matter with aerodynamic diameter less than 2.5 micron) for main cities in central China during the haze period. The CWT method is as follows [45]:

$$
\begin{gathered}
C_{i j}=\frac{\sum_{l=1}^{M} C_{l} T_{i j l}}{\sum_{l=1}^{M} T_{i j l}} \\
W_{i j}=\left\{\begin{array}{c}
1.0\left(3 n_{\text {ave }}<n_{i j}\right) \\
0.7\left(1.5 n_{\text {ave }}<n_{i j}<3 n_{\text {ave }}\right) \\
0.4\left(n_{\text {ave }}<n_{i j}<1.5 n_{\text {ave }}\right) \\
0.2\left(n_{i j}<n_{\text {ave }}\right)
\end{array},\right.
\end{gathered}
$$

where $C_{i j}$ is the weighted average concentration for the grid cell $(i, j), C_{l}$ is the measured concentration at the receptor site on the arrival of trajectory $l$ and $T_{i j l}$ is the resident time in the grid cell $(i, j)$ by trajectory $l$. Then, $C_{i j}$ values were multiplied with a weight $W_{i j}$ defined by Equation (4), where $n_{i j}$ is the number of trajectory points in the grid cell $(i, j)$, and nave is the average number of trajectory points in all grid cells, which contain at last one trajectory point. A resultant $C_{i j}$ with a high value indicates that the air masses traveling over the grid cell $(i, j)$ are associated with high pollutant values at the receptor site.

\section{Results}

\subsection{Spatial Patterns of Aerosol Loading over Central China}

AOD is an important parameter for presenting columnar extinction capacity of aerosol and has been widely used in indicating aerosol loading [46]. Figure 2a shows the mean AOD at $550 \mathrm{~nm}$ from Terra MODIS over central China from 2001 to 2015. Generally, AOD is higher in 
the northern part and lower in the southern part. Two regions with high AOD values (as high as 1.0) have been found in central China. They are urban agglomerations centered at Wuhan and Zhengzhou. The Wuhan-centered city clusters are in the central part along the Yangtze River and the Zhengzhou-centered city clusters are in the north part along the Yellow River. Both regions are characterized by dense population and an advanced economy and have undergone fast development in the past decades. The course of industrialization and urbanization in both regions have consumed substantial fossil fuel and emitted massive anthropogenic aerosol such as nitrate, sulfate, and black carbon $[30,47]$. The surrounding areas of these two regions are also high in AOD values (large than 0.7). A region with secondary AOD values (about 0.8) is spotted in the eastern part, which is located in the Poyang plain. The terrain with low altitude in the central part and high altitude in the surrounding area has restricted aerosol from spreading outside and resulted in high AOD in this region. Compared to the high AOD values in these regions, the AODs in the south and some areas in the eastern part of central China, which are hilly areas, are in the middle and lower levels ranging from 0.4 to 0.7 . The minimum AOD, ranging from 0.3 to 0.5 , appears in the western part of central China. This region is mountainous with high altitude and sparse population.

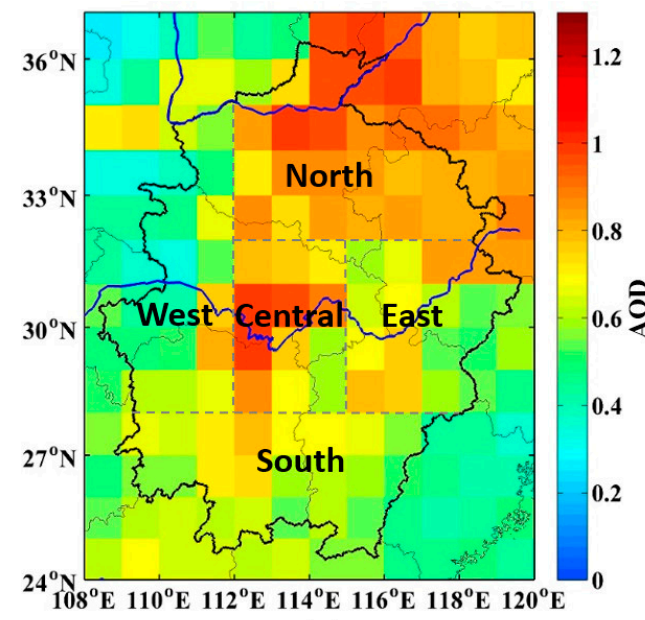

(a)

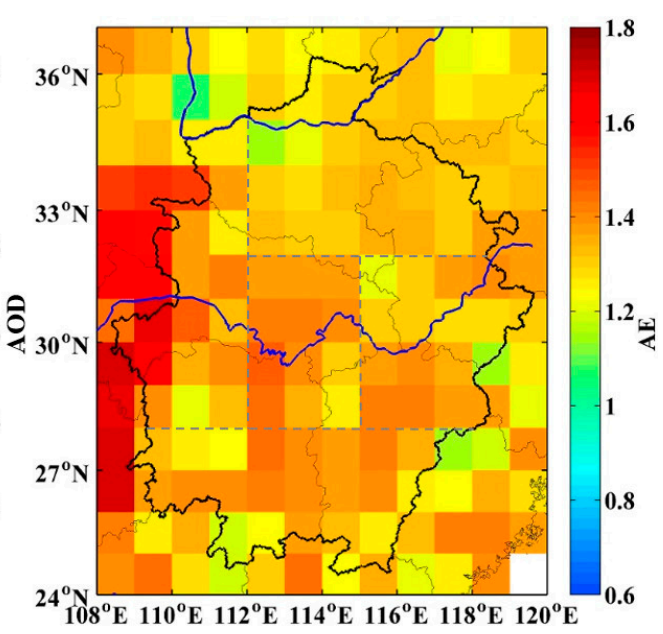

(b)

Figure 2. Annual average (a) AOD and (b) AE over the central China from 2001 to 2015.

The Ångström exponent (AE) indicates the size of aerosol particles. The larger the particle size, the smaller the AE value, for example, dust particles are characterized by large particle size, and AE values are low in areas with abundant dust aerosols [48]. Figure $2 \mathrm{~b}$ presents the spatial distribution of averaged AE from 2001 to 2015. Evidently, AE is larger than 1.2 in most areas, which indicates that the dominated aerosols are small particles, such as nitrate and sulfate aerosols [30]. The AE values are smaller in the northern part than in other regions, which may be due to stronger effects on the northern part by the transported dust from north China [49]. The region located in the north of China's north-south climate demarcation line, and more raised dust caused by a relative dry climate also leads to a smaller AE value [18]. The maximum AE (higher than 1.8) is observed in mountainous areas in the west, which is less influenced by transported and local raised dust as a result of high altitude and vegetation cover [50]. However, small regions have lower AE than the surrounding areas, which could be due to locally raised dust from frequent construction, mining, and low vegetation coverage [51].

Figure 3 shows the seasonally averaged AOD at $550 \mathrm{~nm}$ over central China from 2001 to 2015. The location of high aerosol loading areas do not change with the season, but the AOD values and coverage of high-AOD areas show a significant seasonal variation pattern. In spring, the highest aerosol loading presents in the central part with AOD values larger than 1.2 over Wuhan-centered urban agglomeration. The AOD values are high over other regions: larger than 0.8 in the north and 0.6 in the east and south. High AOD values are mainly due to transported dust from northwest China as 
well as increased agricultural activities in central China in spring [49,52]. The AOD values in summer are smaller than those in spring for most of central China except the north part. The maximum values are in the northern part with AOD values larger than 1.2 over Zhengzhou-centered megalopolis and larger than 1.0 over surrounding regions. High AOD values in summer result from strong gas-particle transformation and hygroscopic growth of aerosol particles under high temperature and humidity conditions [53]. Low AOD values are found in autumn due to lower temperature and humidity in autumn. The rainfall also favors the aerosol diffusion in this season. The Asian winter monsoon brings dry and clean air to this region and causes low AOD values in winters [49]. Regions with AOD values larger than 0.8 are only found over urban agglomeration in the central and northern parts, and AOD values drop in the range of $0.2-0.7$ over the other regions in these seasons.

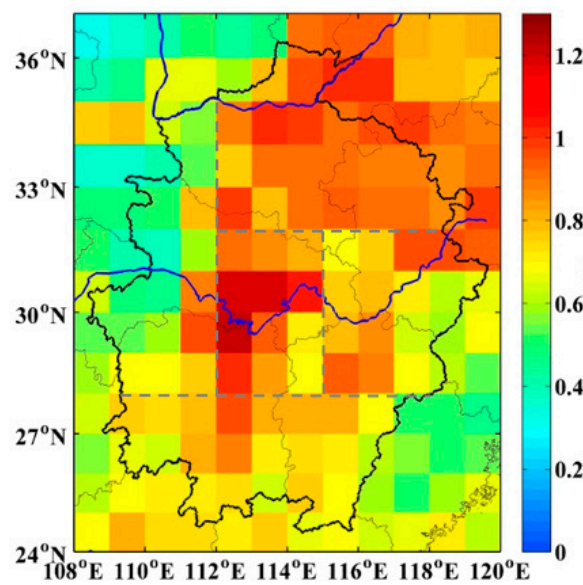

(a)

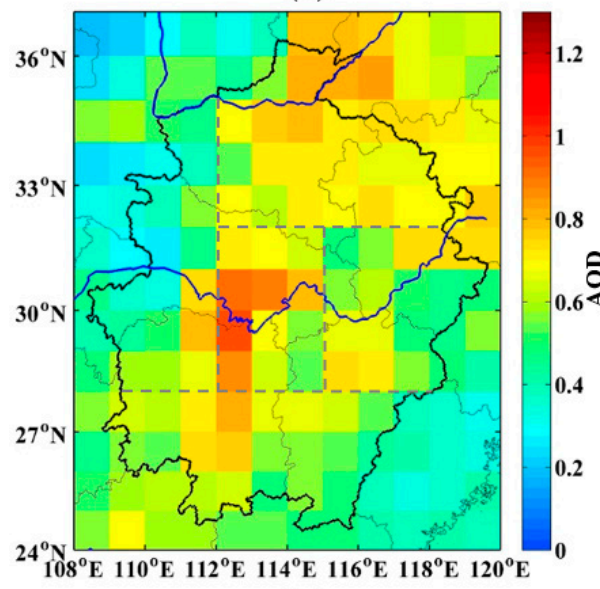

(c)

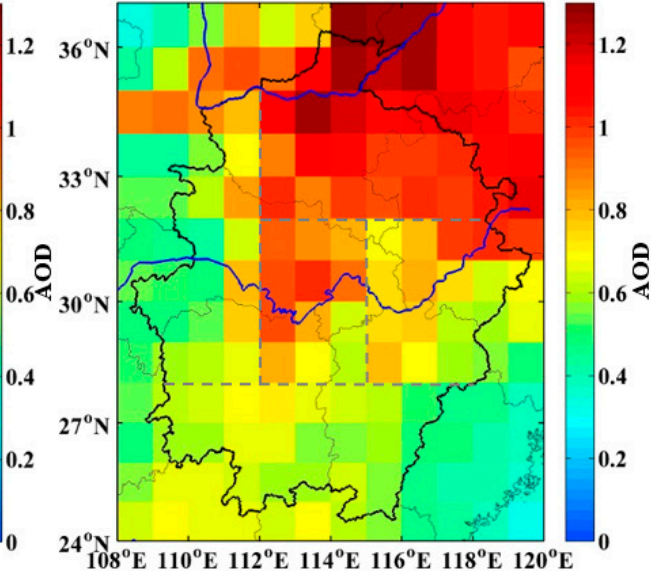

(b)

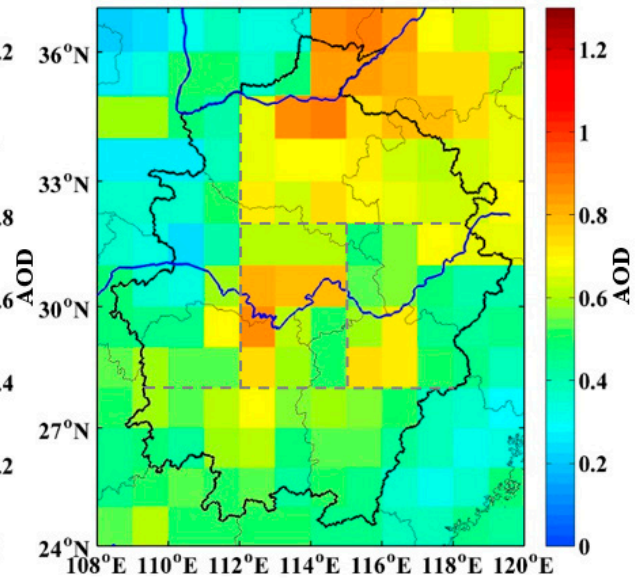

(d)

Figure 3. Seasonal mean AOD from 2001 to 2015 over central China: (a) spring, (b) summer, (c) autumn, and (d) winter.

Figure 4 shows the seasonally averaged distribution of AE from MODIS. The smallest AE values appear in the spring for most central China, indicating a relatively strong influence by large aerosol particles. This condition is mainly due to transported dust aerosol from northwest China [49]. AE in spring shows a distribution of low values in the north and high values in the south, which indicates that the northern region suffers more from transported dust. AE values in other seasons are higher than 1.2 in most regions as they are mainly dominated by small anthropogenic articles emitted by considerable human activities. In addition, these regions are less influenced by transported dust in these seasons [54]. However, high AE values for all seasons are found in mountainous areas in the west. The high altitude of these mountains prevent the invasion of transported dust, and the high 
vegetation cover suppresses the locally raised dust particles, resulting in high AE values of larger than 1.6 throughout the year [50].

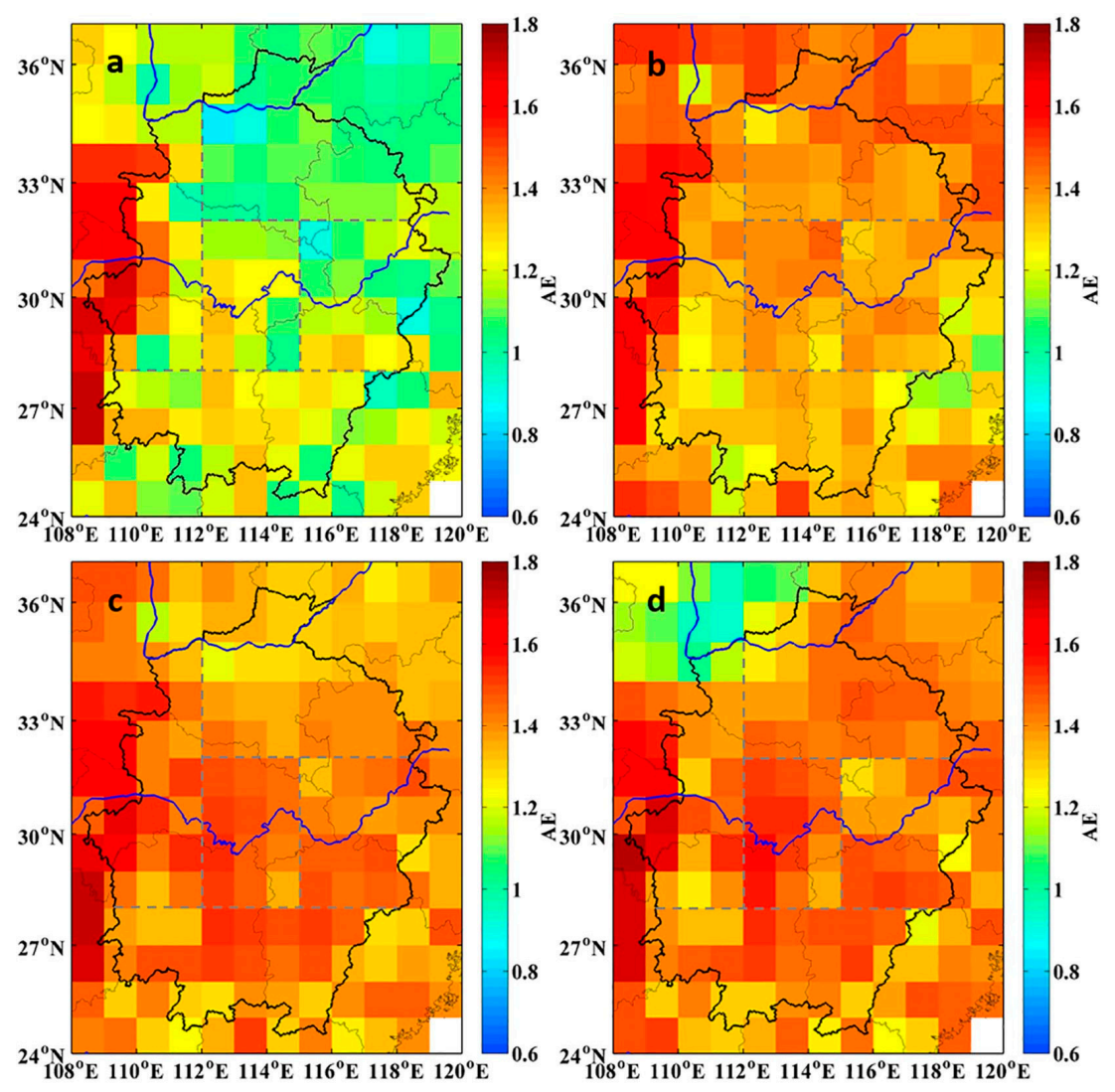

Figure 4. Seasonal mean AE from 2001 to 2015 over central China: (a) spring, (b) summer, (c) autumn, and (d) winter.

\subsection{Inter-Annual Variations of AOD Over Central China}

The AOD trends in central China over the 15 years from 2001 to 2015 were calculated and the distribution is shown in Figure 5a. For deseasonalization, the annual cycle obtained by harmonic regression was subtracted from monthly averaged AOD time series. The trend of the deseasonalized AOD was then computed by fitting a linear model. AOD trend is considered significant when probability value ( $p$ value) of the observations (using the trendless case as null hypothesis) is below the significance level of 5\%. Compared with the spatial distribution of AOD in Figure 1, high growth of AOD appears in regions with high AOD values, while low and negative growth are observed in regions where low aerosol loading exists. The most significant increase in AOD appears in the northern part of the studied area. The rate of increase is approximately larger than 0.012 in certain places. The Wuhan urban agglomeration also shows a significant increasing trend with an increasing rate of approximately 0.008 per year. As both regions have a high population and advanced economy, the increasing AOD over the 15-year period is mainly due to increasing anthropogenic aerosol in the course of urbanization and industrialization. In the eastern part, only AOD over Poyang Plain shows a moderate increase of approximately 0.005 per year. No significant increase has been observed in other regions, and a decreasing trend has even occurred in some places in the south and west. 


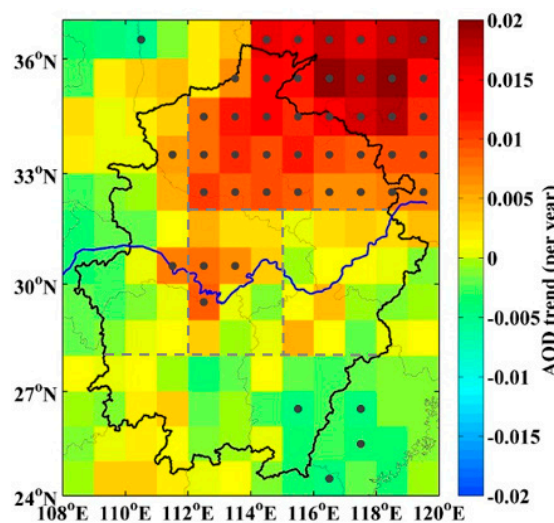

(a)

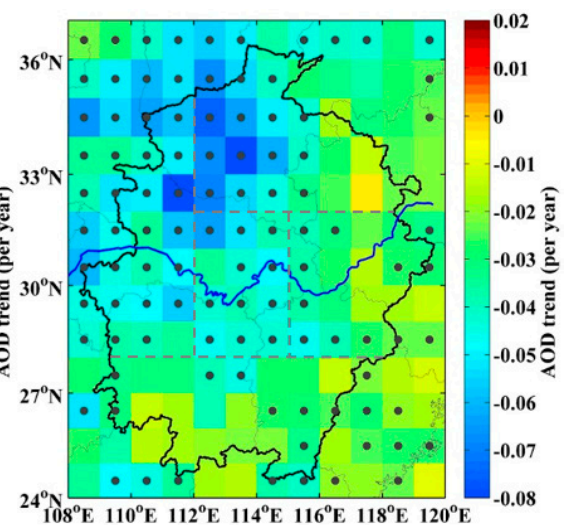

(b)

Figure 5. Deseasonalized AOD trends over central China: (a) from 2001 to 2015, and (b) from 2011 to 2015. Regions with significant trends $(p$ value $<0.05)$ are indicated by dots.

Figure 6 shows the annually averaged time series of AOD over each part of central China during 2001-2015. The annually averaged AOD generally shows its largest values over the northern part, followed by the central part. The AOD values in the eastern and southern regions are close and at middle levels. The minimum values of AOD are observed in the western part. Although the annually averaged AOD values vary considerably among different parts of central China, all parts of the regions show similar variation patterns. AOD in all regions began to increase in 2001, peaked in 2007 , and decreased slightly in the following two years. Thereafter, AOD values increased again from 2010 and reached the maximum in 2011. During the period 2011-2015, a sharp decreasing trend occurred and AOD reached its minimum in 2015. In most parts of central China, including the central, eastern, southern, and western areas, AOD values in 2015 were even lower than those in 2001.

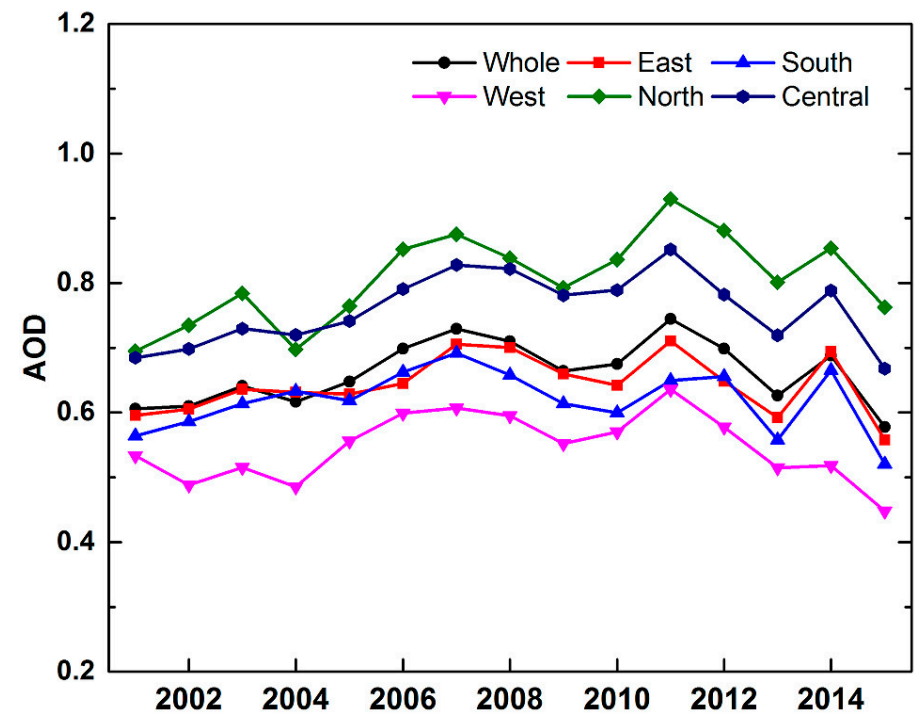

Figure 6. AOD time series over eastern, southern, western, northern, and central parts of central China and entire central China during 2001-2015.

AOD trends over central China were calculated to quantify the sharp descending trend during 2011-2015. As shown in Figure 5b, the entire central China has shown a descending trend. In most areas in the northern, western, and central parts, a strong and significant trend is found with a descending rate larger than 0.04 and even higher than 0.08 per year in some areas in the northern part. A decreasing rate of 0.01 to 0.04 per year is also spotted in the eastern and southern regions. The decreasing AOD 
may be partly due to new air pollution control measures such as restricting industrial denitrification in coal-fired power plants and forbidding straw burning in rural areas in the past few years.

We investigated the variation of annual $\mathrm{SO}_{2}$ and $\mathrm{NO}_{2}$ emissions over provinces in central China during 2011-2015 (Figure 7). The results show that the $\mathrm{NO}_{2}$ and $\mathrm{SO}_{2}$ emissions decrease by $13.97 \%$ and $23.73 \%$ from 2011 to 2015, which would result in considerable emission reduction of sulfate and nitrate aerosols. The maximum emission reduction of $\mathrm{SO}_{2}$ and $\mathrm{NO}_{2}$ are found in Henan province, where the largest decrease of AOD appears. Meteorological parameters such as precipitation play an important role in mobilizing or removing aerosol particles. Figure 8 shows the annual precipitation trend in central China from 2011 to 2015. An increase in rainfall was observed over most areas in central China during 2011-2015; this trend would also be partially responsible for the AOD decrease in central China.
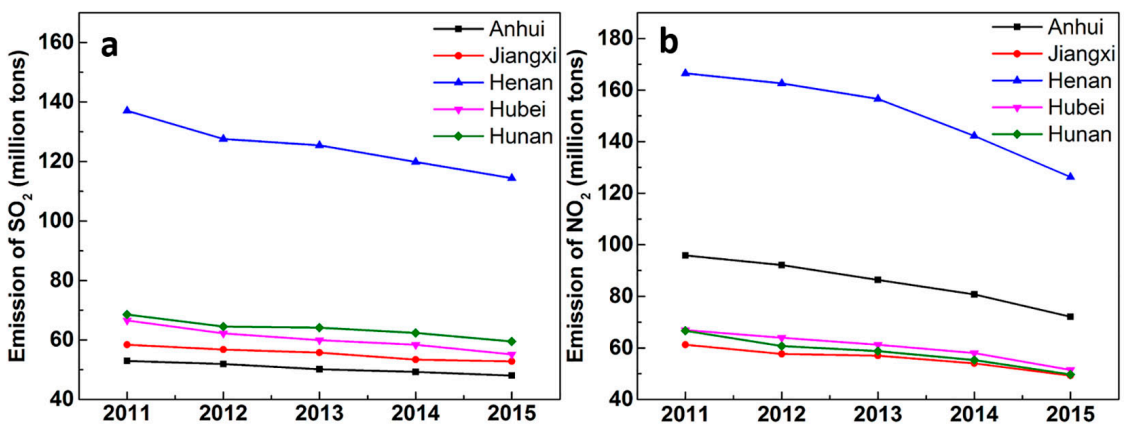

Figure 7. Emissions of (a) $\mathrm{SO}_{2}$ and (b) $\mathrm{NO}_{2}$ over provinces in central China from 2011 to 2015.

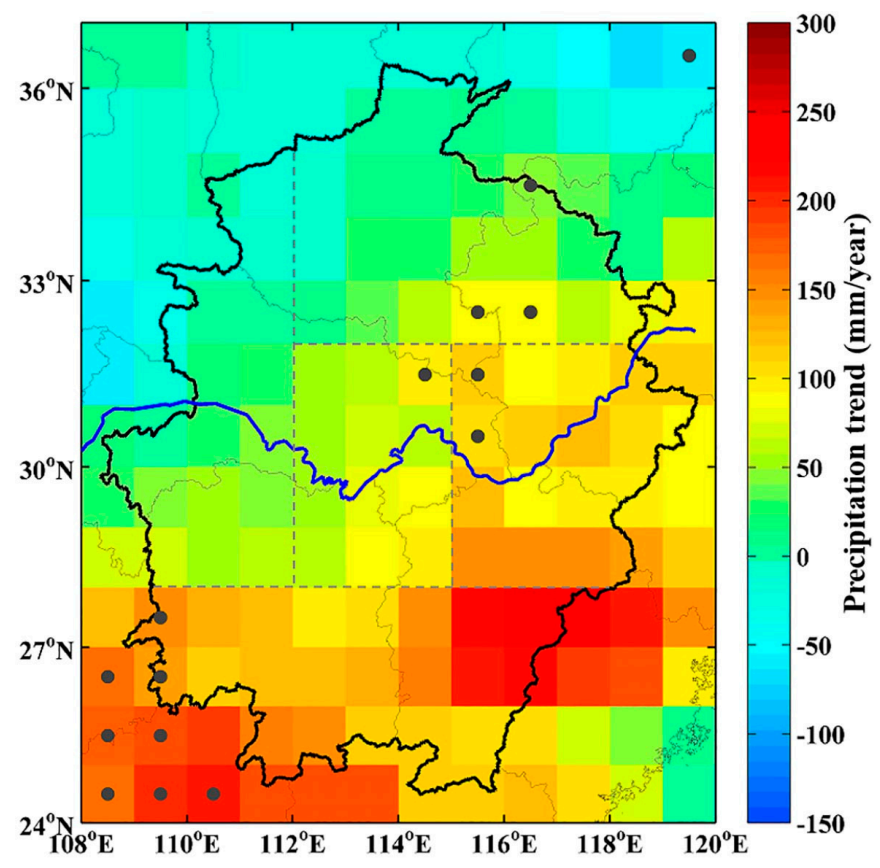

Figure 8. Annual precipitation trend over central China from 2011 to 2015. Regions with significant trends $(p$ value $<0.05)$ are indicated by dots.

\subsection{Comparison of Aerosol Optical and Radiative Properties at Urban and Rural Locations in Central China}

The detailed optical and microphysical properties of aerosol and its radiative effects derived from ground-based sun-photometric observation at an urban and a rural site are investigated as a supplement of large-scale satellite observations of AOD and AE. The city site is located at Wuhan University, in Wuhan, Hubei province [55]. Wuhan is the most developed economic and commercial 
city in central China and is traversed by the Yangtze and Han rivers. The major sources of aerosol are vehicle use and energy consumption. The rural site is located at Mount Song, Dengfeng city in Henan Province [18]. Although aerosol at this site partly comes from local biogenic aerosol emissions and agricultural activities, it is also highly influenced by the transport of polluted air mass from surrounding heavily air-polluted areas such as Zhengzhou in the northeast.

Figure 9a,b show the monthly average AOD in the two sites. Both sites share a similar seasonal variation with high values in spring and summer and low values in autumn and winter. However, AOD in Dengfeng shows more chances of lower values but a wider variation range than that in Wuhan, which may be due to low local aerosol emission at Dengfeng and high transported aerosol loading from surrounding urban areas. The maximum AOD (about 1.1) appear in June for Wuhan, which is followed by a sharp decrease in following months as a result of scavenging effects of precipitation on aerosol in summer. Then AOD values decrease and arrive at its minimum of 0.66 in November. The maximum AOD at Dengfeng presents in July with value of 0.9 and the minimum AOD of 0.48 appears in November.

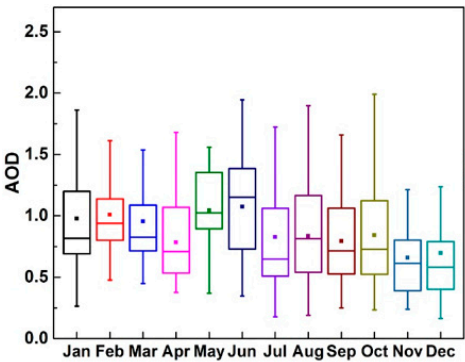

(a)

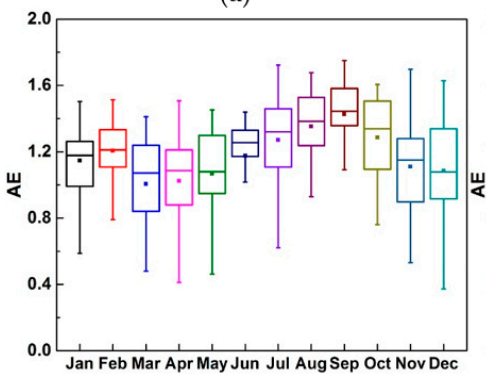

(c)

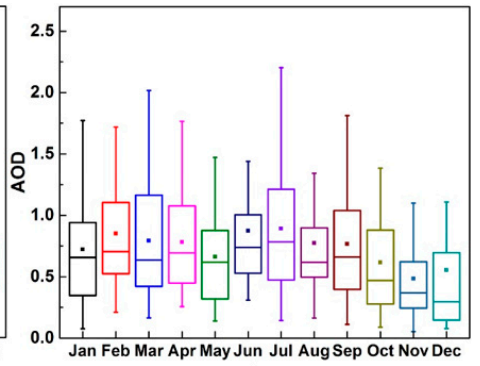

(b)

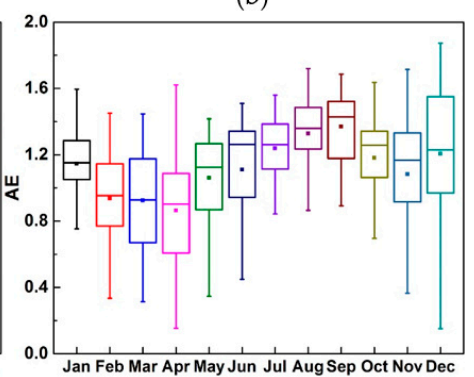

(d)

Figure 9. Monthly variations of AOD at (a) Wuhan and (b) Dengfeng; monthly variations of AE at (c) Wuhan and (d) Dengfeng.

Figure 9c,d show the monthly average AE values in Wuhan and Dengfeng. The two sites share a similar seasonal variation pattern with lowest $\mathrm{AE}$ values in spring and highest values in summer. Small values of AE (approximately 1.0) are found in March and May in Wuhan and the minimum is observed in March. In Dengfeng, low values (less than 0.95) appear from February to April with the minimum in April. The low AE value in late winter and spring implies the relatively strong influence of transported dust aerosol from northern China. High AE values are observed in both sites from June to October when summer monsoon precipitation scavenges larger particles out of the low-atmosphere layer but leaves particles with smaller radii in the upper troposphere through strong vertical convection. Gas-particle transformation may also be strong and secondary anthropogenic aerosols significantly increased, thereby resulting in large Ångström exponents during these months.

The seasonally average ASD is shown in Figure 10. In both sites, ASD shows a bimodal pattern. The fine-mode particles are generally composed of primary and secondary aerosols from human activities, such as vehicle exhaust and fuel combustion, and the coarse-mode particles mainly include dust transported from remote sources and local dust emitted from building construction [30]. Overall, Wuhan has higher maxima peak of fine-mode particles but lower maxima peak of coarse-mode 
particles than that in Dengfeng. In spring, the maxima peaks of coarse mode for both sites are larger than those in other seasons as a result of transported dust aerosol from northern China. However, the coarse-mode peak radii are smaller than those in other seasons, implying that the transported dust aerosol from remote sources have a smaller size than locally raised dust. In summer, fine-mode maxima peaks reach their maximum while coarse-mode maxima peak reach their minimum for both sites. The low maxima peak of the coarse mode is a result of the scavenging effects of precipitation on large particles. Furthermore, fine-mode peak radii are the largest in this season; this condition is possibly associated with high relative humidity and resultant hygroscopic growth of secondary aerosol such as nitration and sulfate. In winter, coarse-mode maxima peak in Wuhan shows a large value close to that in spring but with larger peak radii, which indicates an increase in the amount of locally raised dust with relatively large size.

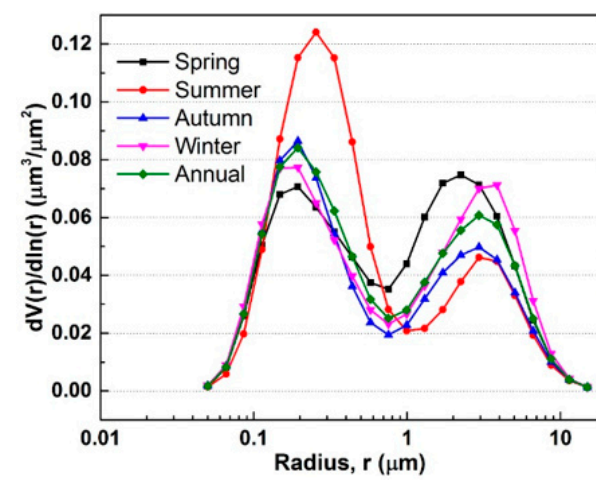

(a)

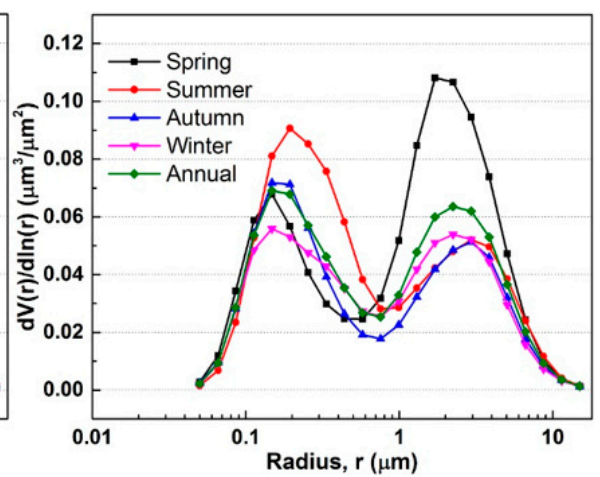

(b)

Figure 10. Annual and seasonal average aerosol volume size distribution in (a) Wuhan and (b) Dengfeng.

Figure 11 presents the annually and seasonally averaged SSA at $440 \mathrm{~nm}$. Evidently, SSA is smaller in Wuhan than that in Dengfeng, indicating stronger absorptivity of aerosol in former site. The annually averaged SSA at $440 \mathrm{~nm}$ are 0.89 for Wuhan and 0.91 for Dengfeng. The highest value of SSA are found in summer in both sites (0.94 for Wuhan and 0.92 for Dengfeng), reflecting the relatively low absorptive components of aerosol in this season. The minimum values of SSA occur in winter in both sites, reflecting the appearance of more absorptive aerosol in this season. The low values of SSA in winter may be due to a combination of increased emissions of absorptive aerosol such as black carbons from winter heating and low-boundary layer height (BLH), which is not conducive to aerosol diffusion [56].

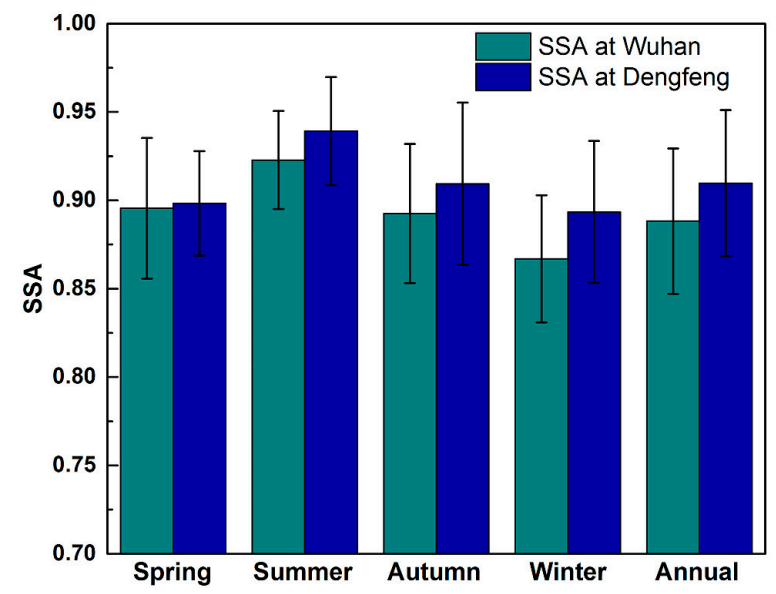

Figure 11. Annual and seasonal average single scattering albedo (SSA) in Wuhan and Dengfeng. 
Figure $12 \mathrm{a}$ shows the annually and seasonally averaged $\mathrm{ARE}_{\mathrm{SW}}$ on the surface in Wuhan and Dengfeng. The negative surface ARESW in both sites indicates that aerosols have a cooling effect on the surface as aerosol loading blocks a large amount of solar radiation from reaching the surface. The annually averaged $\mathrm{ARE}_{\mathrm{SW}}$ is $-48.01 \mathrm{~W} / \mathrm{m}^{2}$ in Wuhan and $-40.02 \mathrm{~W} / \mathrm{m}^{2}$ in Dengfeng, reflecting the higher cooling effects of aerosol in Wuhan. Higher ARESW values are mainly due to higher AOD values in Wuhan; lower SSA may also partially contribute to higher ARE $E_{\text {WW }}$ in Whan.

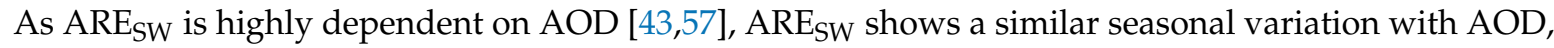
which is high in spring and summer and low in autumn and winter. The maximum ARESW in Wuhan occurs in summer with a value of $-65.00 \mathrm{~W} / \mathrm{m}^{2}$, followed by $-53.88 \mathrm{~W} / \mathrm{m}^{2}$ in spring. ARESW values decrease to $-43.1 \mathrm{~W} / \mathrm{m}^{2}$ in autumn and $-42.27 \mathrm{~W} / \mathrm{m}^{2}$ in winter, respectively. Although AOD in summer is slightly higher than that in spring in Dengfeng, the ARE $\mathrm{SW}_{\mathrm{W}}$ values in these seasons are close, which may result from higher aerosol radiative effect efficiency (REE) in spring. Figure 12b shows the annually and seasonally averaged REE in Wuhan and Dengfeng. The annually averaged REE is $-53.26 \mathrm{~W} / \mathrm{m}^{2}$ in Dengfeng and $-51.38 \mathrm{~W} / \mathrm{m}^{2}$ in Wuhan. The higher value in Dengfeng indicates that aerosols in this area have higher extinction efficiency. The maximum of REE for both sites are observed in spring with a value of approximately $-59 \mathrm{~W} / \mathrm{m}^{2}$. The minimum of REE are observed in winter in Wuhan $\left(-47.86 \mathrm{~W} / \mathrm{m}^{2}\right)$ and in summer in Dengfeng $\left(-48.51 \mathrm{~W} / \mathrm{m}^{2}\right)$. To figure out the factors that drive the seasonal variation of REE, we analyzed the relationship between REE and SSA and AE in Wuhan and Dengfeng; the results are shown in Figure 13a-d. A higher correlation was observed between REE and SSA, and the correlation coefficients were 0.680 for Wuhan and 0.769 for Dengfeng. REE increased with the increase in SSA, thereby indicating that aerosol particles with high absorption were characterized by high REE. Although REE decreased as AE increased, their correlation coefficients were weak at 0.210 for Wuhan and 0.293 for Dengfeng. As discussed above, both sites are mainly loaded by fine-mode aerosol particles. Thus, we checked the relationship between REE and effective radius of fine-mode aerosol (REFF). As shown in Figure 13e,f, a strong correlation was found between REE and REFF in that REE decreased logarithmically as REFF increased. Correlation coefficients were 0.628 and 0.733 for Wuhan and Dengfeng, respectively. According to the Mie theory, when the radii of aerosol particles change from $0.1 \mu \mathrm{m}$ to $0.35 \mu \mathrm{m}$, forward scattering of aerosol particles increases and backward scattering decreases in the ultraviolet and visible spectra, which correspond to the high-spectral-irradiance section in the solar spectrum [58-60]. Thus, the increased forward scattering reduces the extinction efficiency of aerosols on solar radiation and the cooling effect of aerosols on the surface. It should be noted that the changes of forward and backward scattering are unequal for UV, VIS, and NIR spectra. The relatively low SSA and REFF combined with the lowest AE caused by long-range transported dust would be responsible for the maximum of REE in spring.

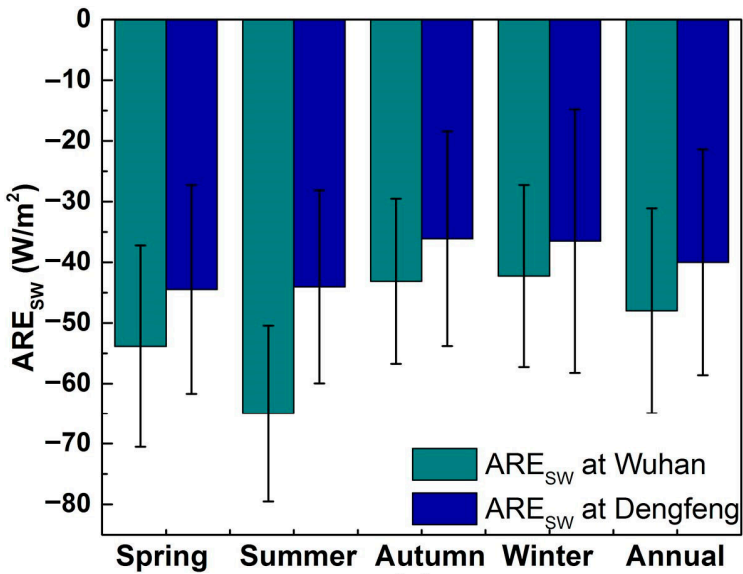

(a)

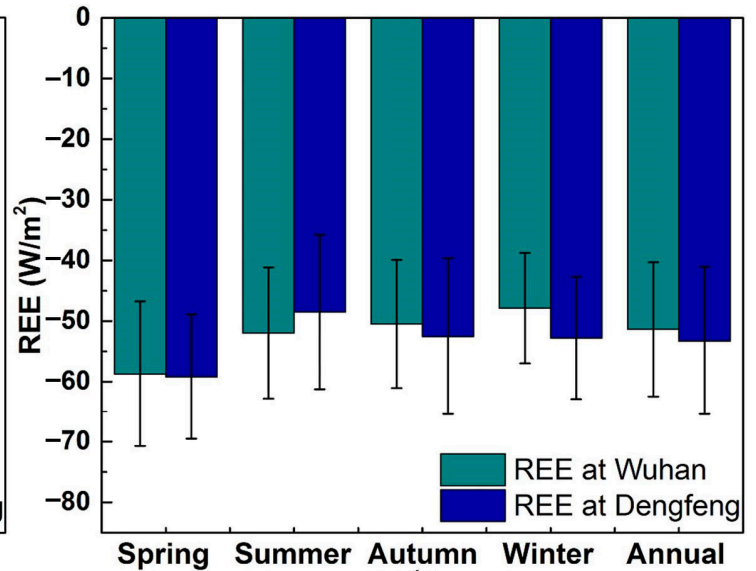

(b)

Figure 12. Annual and seasonal average (a) $A R E_{S W}$ and (b) REE in Wuhan and Dengfeng. 


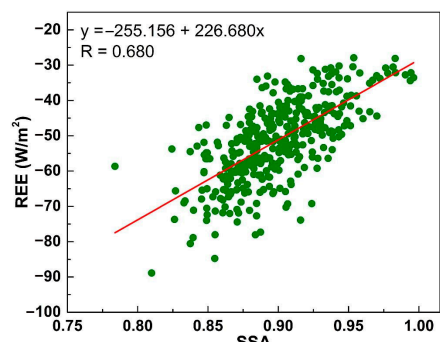

(a)

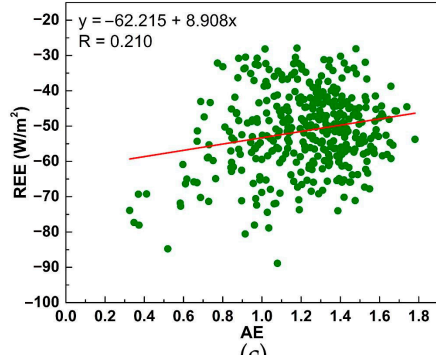

(c)

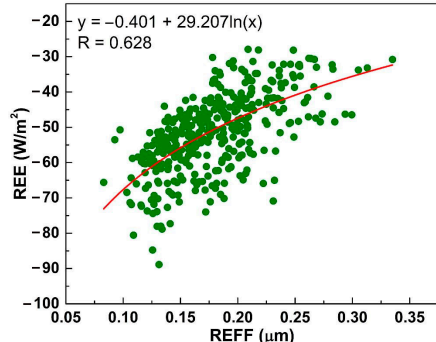

(e)

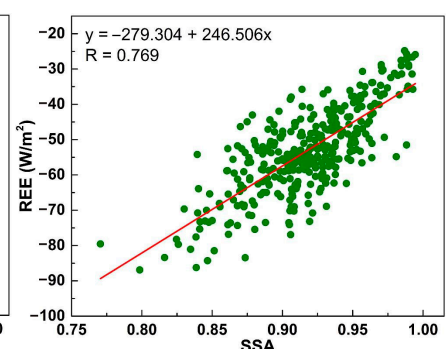

(b)

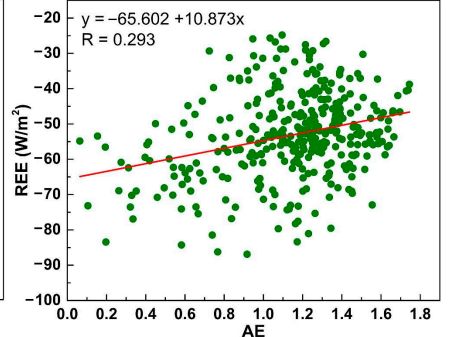

(d)

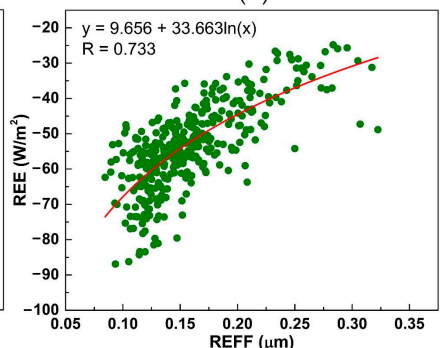

(f)

Figure 13. Dependence of REE on SSA in (a) Wuhan and (b) Dengfeng, AE in (c) Wuhan and (d) Dengfeng, and REFF in (e) Wuhan and (f) Dengfeng.

The component, size, and shape of aerosol not only influence the aerosol radiative effect in the entire SW but also have an unequal impact on various spectral intervals of SW. Figure 14 shows the ARE percentages of UV, VIS, and NIR spectral intervals in the SW spectrum. ARE $E_{U V}$ percentages are close for both sites, and the values are approximately $9 \%$ and 10\% in Wuhan and Dengfeng, respectively. However, large differences are evident in $\mathrm{ARE}_{\mathrm{VIS}}$ and $\mathrm{ARE}_{\mathrm{NIR}}$ fractions between Wuhan and Dengfeng. The ARE VIS fraction is approximately $55 \%$ in Wuhan, which is lower than the value of $58 \%$ in Dengfeng. By contrast, the $\mathrm{ARE}_{\mathrm{NIR}}$ fraction is approximately $36 \%$ in Wuhan, larger than that in Dengfeng. The seasonal variations of $\mathrm{ARE}_{\mathrm{UV}}$ percentage in $\mathrm{ARE}_{\mathrm{SW}}$ are small for Wuhan and Dengfeng, ranging from $9 \%$ to $10 \%$. The maximum ARE $E_{\text {VIS }}$ fraction is observed in summer in both sites with values of approximately $57 \%$ in Wuhan and $61 \%$ in Dengfeng. Simultaneously, ARE ${ }_{\text {NIR }}$ fractions reach a minimum in this season. By contrast, the minimum of the $\mathrm{ARE}_{\mathrm{VIS}}$ fractions are observed in winter at approximately $54 \%$ for Wuhan and $56 \%$ for Dengfeng. We analyzed the factors behind the ARE percentage variation. As the variation of the $A R E_{U V}$ fraction is small and the variation of the $A R E_{N I R}$ fraction is opposite to that of the $A R E_{V I S}$ fraction, the analysis is limited to the $A R E_{V I S}$ fraction only. As shown in Figure 15, although REE exhibited a dependence on SSA, no strong correlation was observed between the ARE $E_{V I S}$ fraction and SSA. However, the ARE $E_{V I S}$ fraction increased with the increase in AE (correlation coefficient of 0.435 in Wuhan and 0.501 in Dengfeng), which indicates that the increase in small aerosol particles contributes to a stronger aerosol radiative effect on the VIS spectrum than that on the NIR spectrum. Furthermore, we analyzed the relationship between the $A R E_{V I S}$ fraction and the ratio (SAR) of surface albedo in near-infrared spectrum to surface albedo in the visible spectrum. As shown in Figure 15e,f, a high correlation exists between the ARE $E_{V I S}$ fraction and SAR, with correlation coefficients of 0.559 and 0.682 for Wuhan and Dengfeng, respectively. The ARE $E_{V I S}$ fraction increases as SAR increases. The surface reflects increased radiation and results in less aerosol 
radiation effect in the NIR spectrum than that in the VIS spectrum with the increase in SAR. Figure 16 shows the annual and seasonal SAR in Wuhan and Dengfeng. The SAR values in Wuhan are less than those in Dengfeng, which are responsible for a lower AREVIS fraction in Wuhan. The maximum and minimum of SAR in both sites occur in summer and winter, respectively, which may be part of the reason for the lowest $A R E_{V I S}$ fraction in winter and the highest in summer.

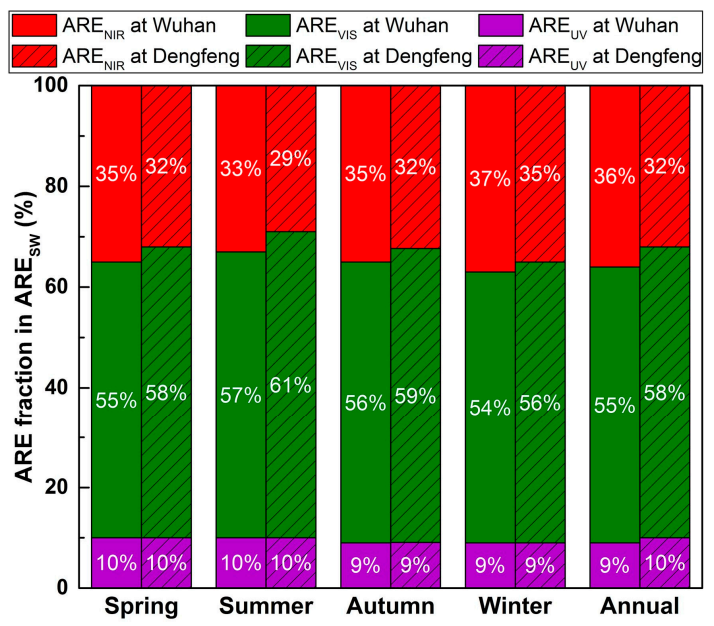

Figure 14. Annual and seasonal average ARE fraction of UV, VIS, and NIR in ARESW in Wuhan and Dengfeng.
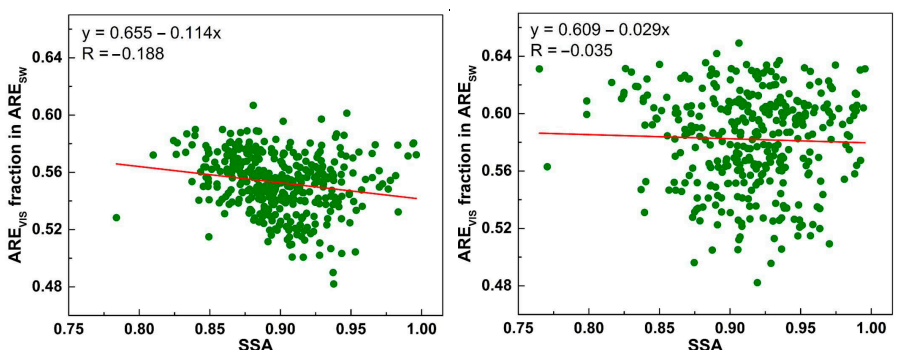

(a)
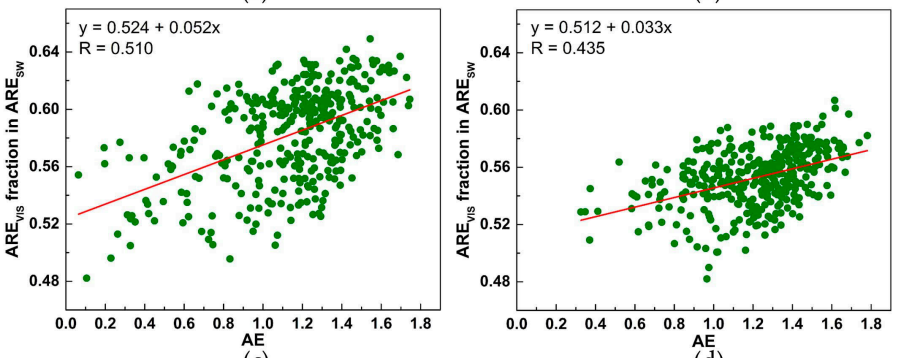

$\stackrel{A E}{(d)}$

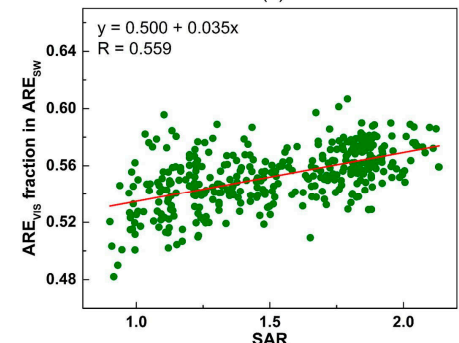

(e)

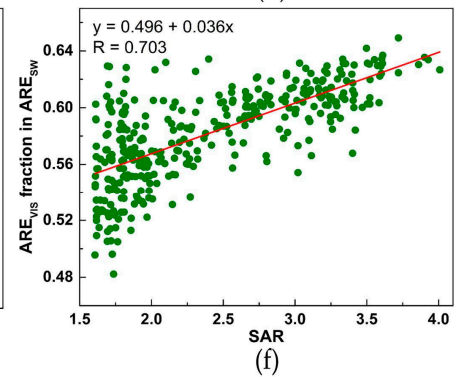

Figure 15. Dependence of REE on SSA in (a) Wuhan and (b) Dengfeng, AE in (c) Wuhan and (d) Dengfeng, and SAR in (e) Wuhan and (f) Dengfeng. 


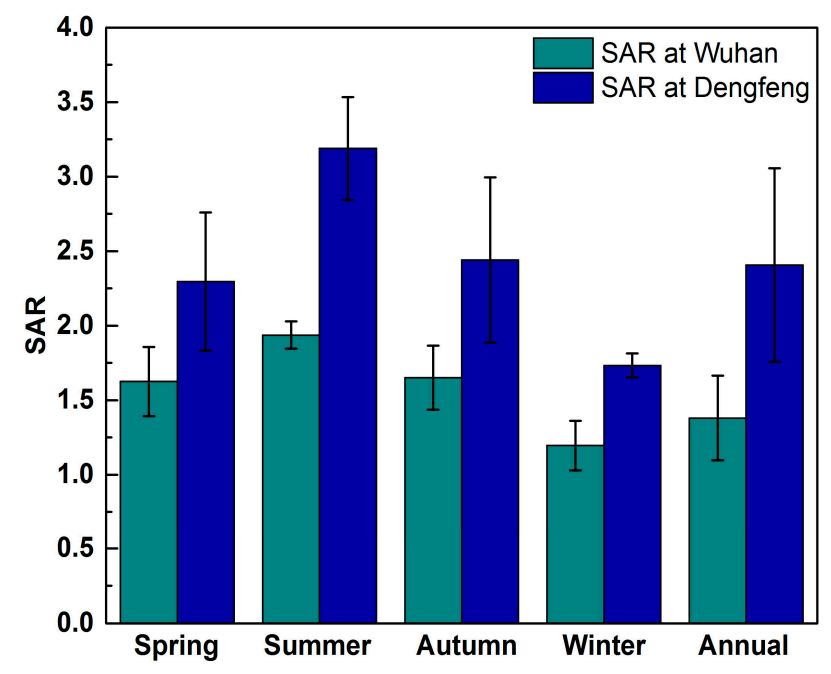

Figure 16. Annual and seasonal average SAR in Wuhan and Dengfeng.

\subsection{Source Region Analysis during Haze Periods in Central China}

Serious air pollution and frequent haze events have occurred in winter in central China. Figure 17 shows cases of MODIS true color images captured during haze periods from 11 December 2014 to 26 February 2015. Extensive haze was clearly visible over most regions in central China. Simultaneously, widespread haze was also observed in the adjacent regions, such as the Yangtze River Delta in the east, Shandong province in the northeast, Jing-Jin-Ji area in the north, and Shaanxi province in the northwest. Back trajectories from the HYSPLIT model and CWT method were used to analyze the contributions of surrounding haze regions to central China and potential sources of pollutants of main cities in central China. These cities are Zhengzhou in the north, Hefei in the east, Wuhan in the central part, and Changsha in the south of central China. Zhengzhou is close to the Jing-Jin-Ji area and Shandong province, and Hefei is close to the Yangtze River Delta, which are haze regions. Wuhan and Changsha are located in the Jianghan and Dongting Plain, an area that is surrounded by hills and mountains. The topographic conditions are disadvantageous to the diffusion of local emission and also limit the invasion of surrounding emissions in certain directions. Back trajectories from the HYSPLIT model were clustered for all data from 11 December 2014 to 26 February 2015; mean trajectories are shown in Figure 18. In general, air masses in central China during the study period were mainly from the north, northwest, and west of China. The cluster with the largest proportion of back trajectories for Zhengzhou came from the Jing-Jin-Ji area and passed by Shandong province. This cluster was characterized by short-range trajectories and low altitudes. The slow-moving short-range trajectories may have been associated with higher concentration of pollutants because of the increased residence time of air parcels over potential source regions. The low altitude of the cluster may also have contributed to the transport of more pollutants to Zhengzhou as the boundary layer height was low and pollutants tend to be concentrated in the lower atmospheric layers during haze periods. For Hefei, the cluster with the largest proportion of trajectories came from the west, followed by the cluster from the Jing-Jin-Ji area and passing through the Shandong Peninsula. Both two clusters, which have a short range and low height, may have brought a large amount of pollutants to Hefei. Few trajectories are observed from the Yangtze River Delta, although Hefei is close to this region. For Wuhan, $47.86 \%$ of the back trajectories came from nearby areas, floating over the Jianghan and Dongting Plain at a low altitude. For Changsha, nearly half of the back trajectories came from regions in the Jianghan and Dongting Plain and $7.21 \%$ came from the south, which indicated that the southern part of central China was invaded by pollutants from south China, especially from Guangdong province, which is economically developed and polluted. 


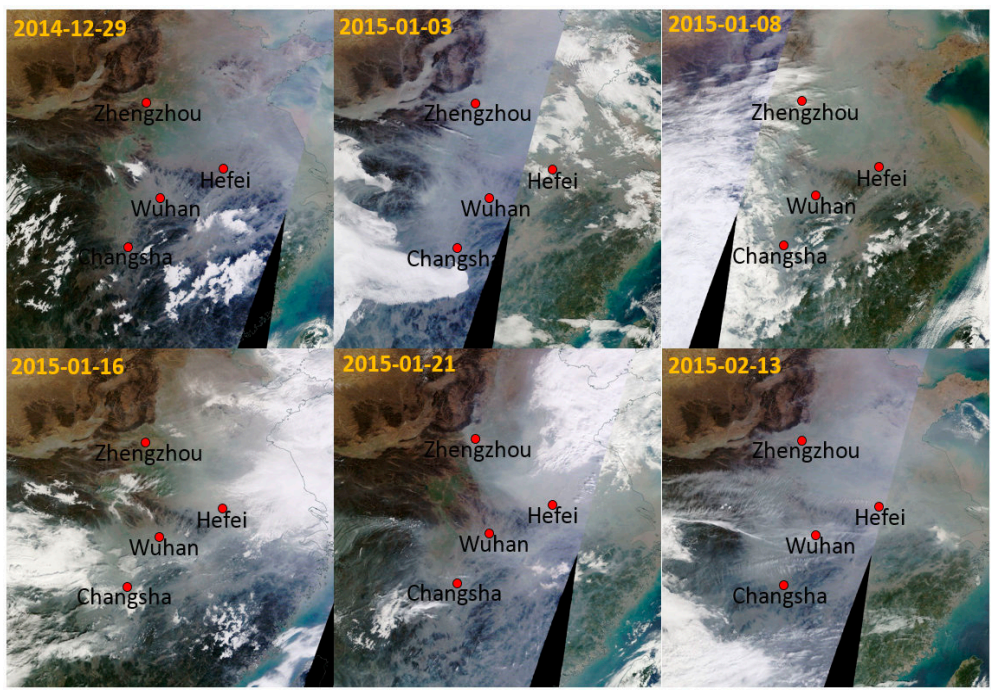

Figure 17. Cases of Terra 1-km MODIS true color images of regional haze pollution over central China during haze events from 11 December 2014 to 26 February 2015.

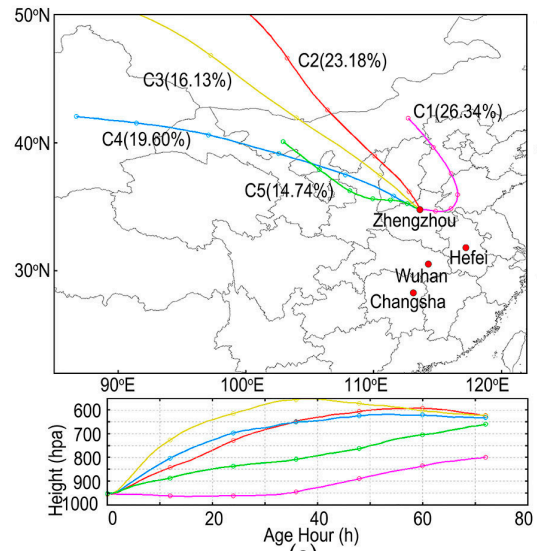

(a)
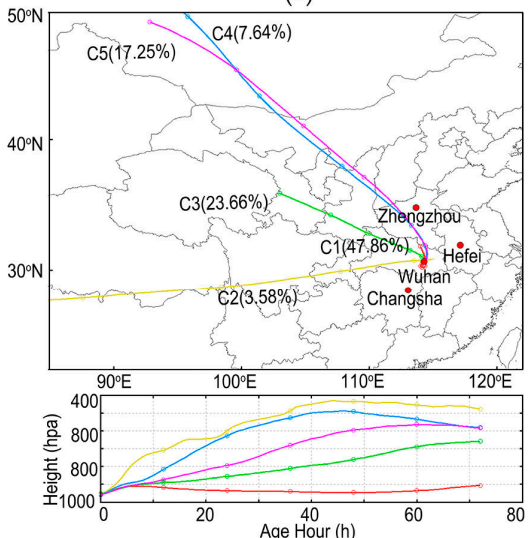

(c)

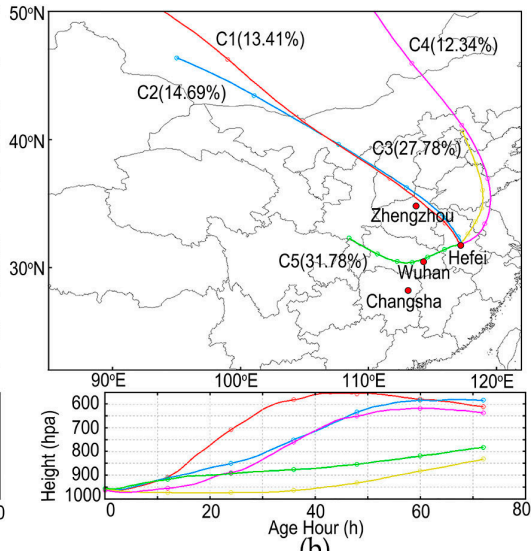

(b)

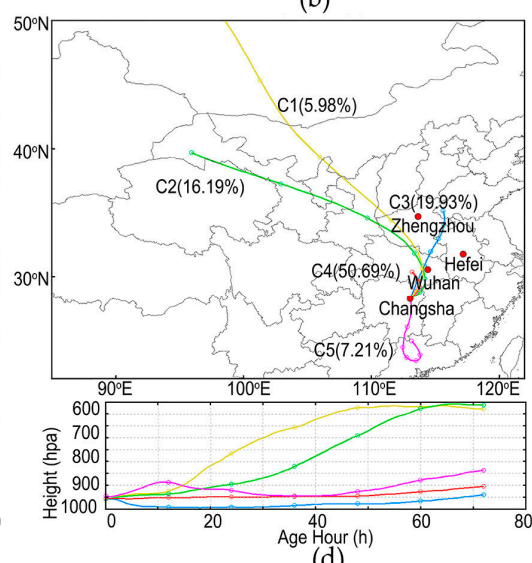

(d)

Figure 18. Cluster analysis of 72-h back trajectories at $500 \mathrm{~m}$ on horizontal and vertical for (a) Zhengzhou, (b) Hefei, (c) Wuhan, and (d) Changsha from 11 December 2014 to 26 February 2015.

Figure 19 shows the distribution of CWT values for $\mathrm{PM}_{2.5}$ in Zhengzhou, Hefei, Wuhan, and Changsha from 11 December 2014 to 26 February 2015. Air parcels with high PM 2.5 mass concentration in Zhengzhou mainly came from the north of Shannxi province to the north of Henan province. These areas are major sources of fine-mode particles during haze events and can exert a strong 
impact on the haze breakout dynamics and severity of haze in Zhengzhou. However, the Jianghan and Dongting Plain contributed minimally to pollutants in Zhengzhou because of the blocking of mountains in the north of Jianghan and Dongting Plain. The sources that produce high $\mathrm{PM}_{2.5}$ in Hefei were in the west of Shandong and Anhui provinces, while the air parcels from the Yangtze River had a minimal impact on air pollution in Hefei. The potential source regions for Wuhan coincided with those for Changsha. Both cities located in the Jianghan and Dongting Plain and the surrounding hills and mountains blocked the diffusion of locally emitted pollutants, which would be responsible for the serious air pollution and frequent haze events in this region. A zone of high CWT values for PM $\mathrm{PM}_{2.5}$ was observed in the south of Changsha, which confirmed the invasion of pollutants from south China in winter.

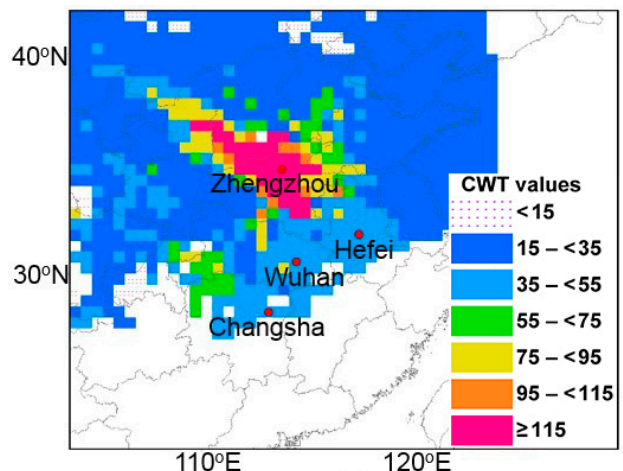

(a)

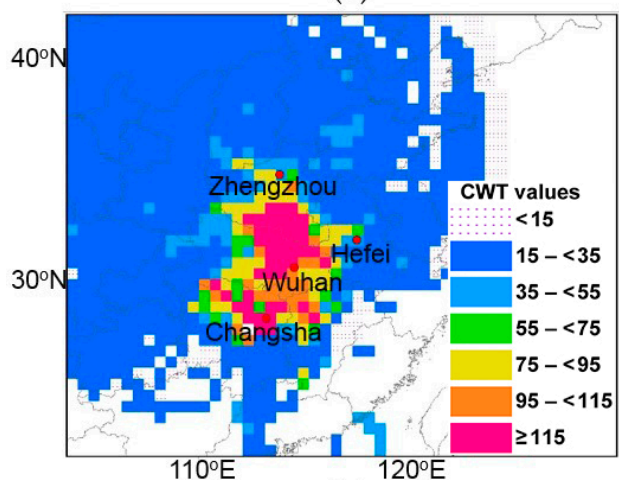

(c)

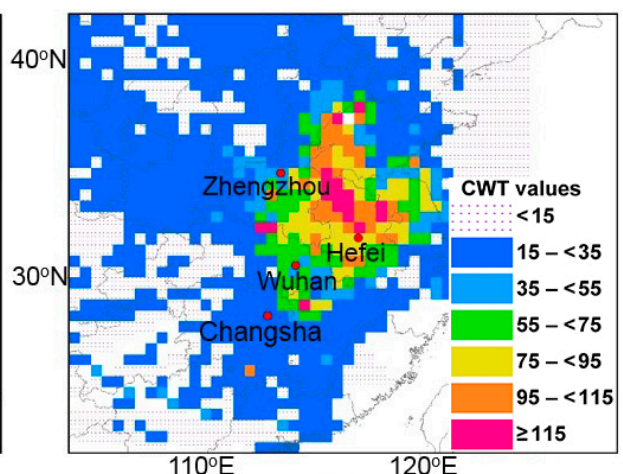

(b)

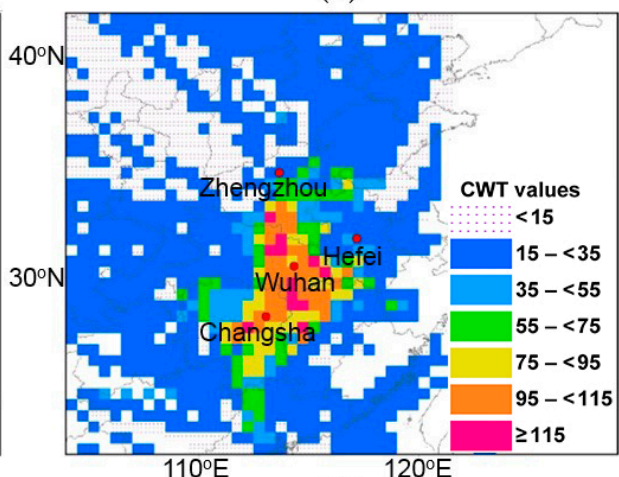

(d)

Figure 19. CWT method analysis maps for $\mathrm{PM}_{2.5}$ in (a) Zhengzhou, (b) Hefei, (c) Wuhan, and (d) Changsha from 11 December 2014 to 26 February 2015.

\section{Discussion}

To assess the influence of aerosol optical properties on radiation simulation and ARE calculation, we conducted sensitivity tests for ARE calculation by adding a perturbed value for each aerosol parameter inputted in the libRadtran model. The sensitivity test is based on two steps: first, ARE was calculated using the measured values as input parameters, obtaining the non-perturbed results. Secondly, we calculated ARE by adding a perturbed value for an input aerosol parameter and keeping other parameters unchanged, thereby obtaining a perturbed result. This step is repeated to obtain perturbed results for all the input aerosol parameters, such as AOD, SSA, and AF. A similar strategy has been adopted for uncertainty estimation of ARE calculation in previous studies [61]. The perturbed values of AOD, SSA, and AF values were selected based on the uncertainties of aerosol property inversion. AOD was perturbed by \pm 0.01 , SSA was perturbed by \pm 0.03 , and AF was perturbed by \pm 0.02 . Table 1 shows the absolute changes and relative deviation of ARE between the non-perturbed and perturbed results. An increase of 0.01 in AOD from the measurements causes an ARE increase of $4.66-8.00 \%$. By contrast, a decrease of 0.01 in AOD results in a decrease with similar magnitudes. 
The largest ARE change in this analysis is associated with SSA uncertainty. An increase of 0.03 in SSA provides mean decreases of $9.17-9.85 \%$ for ARE. A larger SSA causes increased scattering and reduced absorption by aerosol. Therefore, the diffuse radiation arriving on the surface increases, thereby reducing the extinction effect of aerosol on solar radiation. For AF, an increase of 0.02 in $\mathrm{AF}$ causes a $2.35-2.60 \%$ decrease in ARE. An increase in AF resulted in increasing scattering radiation in the forward direction and a larger downward flux. The increasing forward scattering would reduce the extinction effect of aerosols on the solar radiation and the cooling effect of aerosols on the surface.

Table 1. Aerosol parameter perturbations used in radiative perturbation analysis and corresponding ARE changes (relative deviation is indicated by parenthesis).

\begin{tabular}{|c|c|c|c|}
\hline Parameter & Perturbation & Change of ARE in Wuhan $\mathrm{W} / \mathrm{m}^{2}(\%)$ & Change of ARE in Dengfeng W/m $/ \mathrm{m}^{2}(\%)$ \\
\hline AOD & $0.01 \mid-0.01$ & $-3.57(4.66) \mid 3.62(-4.72)$ & $-3.13(8.00) \mid 3.18(-8.13)$ \\
\hline SSA & $0.03 \mid-0.03$ & $8.51(-9.85) \mid-8.25(9.70)$ & $6.21(-9.17) \mid-6.40(10.10)$ \\
\hline $\mathrm{AF}$ & $0.02 \mid-0.02$ & $1.98(-2.35) \mid-1.93(2.30)$ & $1.57(-2.60) \mid-1.52(2.50)$ \\
\hline
\end{tabular}

\section{Conclusions}

The spatial distribution and temporal variation of aerosol loading and detailed aerosol optical and microphysical properties was investigated over central China using long-term series of AOD and AE from MODIS observations, combined with ground-based sun-photometric measurements in an urban and a rural site. High AOD appeared in the north and central part with dense population and advanced economy while low values were found in the hilly area of the east and south part and mountainous area in the west part. AOD values were high in spring and summer and low in autumn and winter. The region with highest AOD varied with the seasons, specifically in the central part for spring and in the northern part for summer. Most regions were dominantly loaded with small aerosol particles with a significant influence of long-distance transported dust in spring. During 2011-2015, a strong and significant descending trend was observed in the entire region with a maximum descending rate of -0.08 per year in the northern and western parts. The descending trend is related to the decreasing emissions of aerosols and increasing rainfall in the past few years.

Detailed optical and microphysical properties of aerosol and its radiative effects are investigated over an urban site (Wuhan) in the central part and a rural site (Dengfeng) in the northern part. The aerosol properties were derived from sun-sky radiometer observations in Wuhan and Dengfeng and used as input to a radiative transfer model to simulate ultraviolet, visible, near-infrared, and shortwave irradiance and then calculate the corresponding ARE. Sensitivity tests were conducted to assess the sensitivity of ARE to uncertainties in aerosol optical properties. The results show that a 0.01 increase in AOD causes a 4.66-8.00\% increase in ARE, an increase of 0.03 in SSA causes a 9.17-9.85\% decrease in ARE, and an increase of 0.02 in AF results in 2.35-2.60\% decrease in ARE. The seasonal variations of AOD and AE were close for the two sites, but the AOD and AE values are larger in Wuhan than those in Dengfeng, indicating that Wuhan is characterized by larger aerosol loading and more small particles. Wuhan has a higher maxima peak of fine mode of ASD and lower maxima peak of coarse mode than those in Dengfeng. Both sites show the highest maxima peak of fine mode and lowest maxima peak of coarse mode in spring, with smaller radii of coarse-mode particles than in other seasons, implying that the size of transported dust is smaller than that of locally raised ones. In summer, the maxima peak of fine mode and peak radii reached their maximum for both sites, which may be due to the strong hygroscopic growth of aerosol particles. SSA is smaller in Wuhan than that in Dengfeng, indicating a stronger absorptivity of aerosol in the former. The maximum and minimum SSA at $440 \mathrm{~nm}$ for both sites are recorded in summer and winter, respectively, indicating the presence of relatively low absorptive aerosol in summer and high in winter.

The annual average ARESW is $-48.01 \mathrm{~W} / \mathrm{m}^{2}$ in Wuhan and $-40.02 \mathrm{~W} / \mathrm{m}^{2}$ in Dengfeng, reflecting the higher cooling effects of aerosol in the former. The annual average REE is $-51.38 \mathrm{~W} / \mathrm{m}^{2}$ in Wuhan and $-53.26 \mathrm{~W} / \mathrm{m}^{2}$ in Dengfeng, which indicates that aerosol in the latter has higher extinction 
efficiency. $A R E_{S W}$ shows a similar seasonal variation pattern with the AOD values, which are high in spring and summer and low in autumn and winter. REE is strongly influenced by the variation of SSA, and aerosol particles with high absorption are characterized by high REE. The correlation between REE and AE is weak while a strong correlation is observed between REE and REFF, where REE decreased logarithmically as REFF increased. The component, size, and shape of aerosol have an uneven impact on various spectral intervals of shortwave. The ARE $E_{V I S}$ fraction is approximately $55 \%$ in Wuhan, which is lower than $58 \%$ in Dengfeng. The maximum ARE $E_{V I S}$ fraction occurs in summer in both sites at approximately 57\% in Wuhan and 61\% in Dengfeng. The AREVIS fraction increased with AE, which indicates that the increases of small aerosol particles contribute to an increased aerosol radiative effect in the visible spectrum than in the near-infrared spectrum. A high correlation is observed between the AREVIS fraction and SAR, with correlation coefficients of 0.559 and 0.682 in Wuhan and Dengfeng, respectively. The SAR values in Wuhan are less than those in Dengfeng, which are

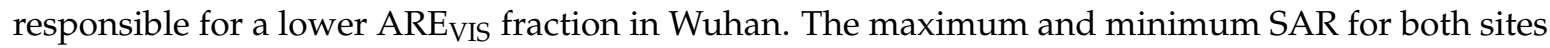
are observed in summer and winter, respectively, which may be responsible for the lowest AREVIS fraction in winter and the highest in summer.

Serious air pollution and frequent haze events have occurred in central China in winter. Back trajectories from the HYSPLIT model and CWT method were used to analyze the contributions of surrounding haze regions to central China and potential sources of pollutants for main cities in central China. Air particles with high $\mathrm{PM}_{2.5}$ mass concentration for Zhengzhou mainly came from the north of Shannxi province to the north of Henan province. However, the Jianghan and Dongting Plain contributed minimally to pollutants in Zhengzhou because of the blocking of mountains in the north of Jianghan and Dongting Plain. The sources that produce high $\mathrm{PM}_{2.5}$ in Hefei were found to be in the west of Shandong and Anhui provinces while the air particles from the Yangtze River had a minimal impact on air pollution in Hefei. The main potential source regions for Wuhan and Changsha were in the Jianghan and Dongting Plain, and the surrounding hills and mountains blocked the locally emitted pollutants from diffusion, which would be responsible for the serious air pollution and frequent haze events in this region. A zone of high CWT values for $\mathrm{PM}_{2.5}$ was found in the south of Changsha, which confirmed the invasion of pollutants from south China in winter.

A detailed analysis of the optical, microphysical, and radiative properties of aerosols is useful for monitoring and assessing the climatic and environmental changes over central China. The findings enhance our understanding of the mechanisms that govern ARE variation and contribute to an accurate evaluation of the radiative effect and radiative feedback of aerosols on the climate.

Acknowledgments: This work was financially supported by the National Natural Science Foundation of China (Grant No. 41127901, No. 41401498, and No. 41601044), the Program for Innovative Research Team in University of the Ministry of Education of China (Grant No. IRT1278), the Special Fund for Basic Scientific Research of Central Colleges, China University of Geosciences, Wuhan (Grant No. CUG150631 and CUGL170401), and the Specialized Research Fund for the Doctoral Program of Higher Education of China (Grant No. 20120141120010). We thank the MODIS scientific teams for the provision of MODIS data and the NOAA Air Resources Laboratory (ARL) for the HYSPLIT transport and dispersion model used in this study.

Author Contributions: Ming Zhang, Lunche Wang, and Wei Gong designed the research; Lunche Wang, Ming Zhang, and Yingying Ma performed the experiments and analyzed the data; Ming Zhang and Lunche Wang wrote the manuscript; Lunche Wang, Wei Gong, and Boming Liu revised the manuscript.

Conflicts of Interest: The authors declare no conflict of interest.

\section{References}

1. Stocker, T. Climate Change 2013: The Physical Science Basis: Working Group I Contribution to the Fifth Assessment Report of the Intergovernmental Panel on Climate Change; Cambridge University Press: Cambridge, UK, 2014.

2. Albrecht, B.A. Aerosols, cloud microphysics, and fractional cloudiness. Science 1989, 245, 1227-1231. [CrossRef] [PubMed] 
3. Bi, J.; Huang, J.; Fu, Q.; Wang, X.; Shi, J.; Zhang, W.; Huang, Z.; Zhang, B. Toward characterization of the aerosol optical properties over loess plateau of NorthWestern China. J. Quant. Spectrosc. Radiat. Transf. 2011, 112, 346-360. [CrossRef]

4. Ocko, I.B.; Ramaswamy, V.; Ming, Y. Contrasting climate responses to the scattering and absorbing features of anthropogenic aerosol forcings. J. Clim. 2014, 27, 5329-5345. [CrossRef]

5. Menon, S.; Hansen, J.; Nazarenko, L.; Luo, Y. Climate effects of black carbon aerosols in China and India. Science 2002, 297, 2250-2253. [CrossRef] [PubMed]

6. Li, Z.; Niu, F.; Fan, J.; Liu, Y.; Rosenfeld, D.; Ding, Y. Long-term impacts of aerosols on the vertical development of clouds and precipitation. Nat. Geosci. 2011, 4, 888-894. [CrossRef]

7. Huang, Z.; Huang, J.; Bi, J.; Wang, G.; Wang, W.; Fu, Q.; Li, Z.; Tsay, S.C.; Shi, J. Dust aerosol vertical structure measurements using three mpl lidars during 2008 China-Us joint dust field experiment. J. Geophys. Res. Atmos. 2010, 115, 1307-1314. [CrossRef]

8. Xia, X. Parameterization of clear-sky surface irradiance and its implications for estimation of aerosol direct radiative effect and aerosol optical depth. Sci. Rep. 2015, 5, 14376. [CrossRef] [PubMed]

9. Penner, J.E.; Dong, X.; Chen, Y. Observational evidence of a change in radiative forcing due to the indirect aerosol effect. Nature 2004, 427, 231-234. [CrossRef] [PubMed]

10. Lohmann, U.; Diehl, K. Sensitivity studies of the importance of dust ice nuclei for the indirect aerosol effect on stratiform mixed-phase clouds. J. Atmos. Sci. 2006, 63, 968-982. [CrossRef]

11. Sekiguchi, M.; Nakajima, T.; Suzuki, K.; Kawamoto, K.; Higurashi, A.; Rosenfeld, D.; Sano, I.; Mukai, S. A study of the direct and indirect effects of aerosols using global satellite data sets of aerosol and cloud parameters. J. Geophys. Res. Atmos. 2003, 108, 2025-2041. [CrossRef]

12. Ocko, I.B.; Ramaswamy, V.; Ginoux, P.; Ming, Y.; Horowitz, L.W. Sensitivity of scattering and absorbing aerosol direct radiative forcing to physical climate factors. J. Geophys. Res. Atmos. 2012, 117, 20203. [CrossRef]

13. Kristjánsson, J.E. Studies of the aerosol indirect effect from sulfate and black carbon aerosols. J. Geophys. Res. Atmos. 2002, 107. [CrossRef]

14. Ramabhadran, T.E.; Peterson, T.W.; Seinfeld, J.H. Dynamics of aerosol coagulation and condensation. Aiche J. 2010, 22, 840-851. [CrossRef]

15. Singh, R.P.; Dey, S.; Tripathi, S.N.; Tare, V.; Holben, B. Variability of aerosol parameters over Kanpur, Northern India. J. Geophys. Res. Atmos. 2004, 109, 2543-2552. [CrossRef]

16. Xie, Y.; Li, Z.; Li, D.; Xu, H.; Li, K. Aerosol optical and microphysical properties of four typical sites of sonet in China based on remote sensing measurements. Remote Sens. 2015, 7, 9928-9953. [CrossRef]

17. Huang, J.; Fu, Q.; Su, J.; Tang, Q.; Minnis, P.; Hu, Y.; Yi, Y.; Zhao, Q. Taklimakan dust aerosol radiative heating derived from calipso observations using the fu-liou radiation model with ceres constraints. Atmos. Chem. Phys. 2009, 9, 4011-4021. [CrossRef]

18. Wang, L.; Gong, W.; Singh, R.P.; Xia, X.; Che, H.; Zhang, M.; Lin, H. Aerosol optical properties over mount song, a rural site in central China. Aerosol Air Qual. Res. 2015, 15, 2051-2064. [CrossRef]

19. Remer, L.A.; Kaufman, Y.; Tanré, D.; Mattoo, S.; Chu, D.; Martins, J.V.; Li, R.-R.; Ichoku, C.; Levy, R.; Kleidman, R. The modis aerosol algorithm, products, and validation. J. Atmos. Sci. 2005, 62, 947-973. [CrossRef]

20. Holben, B.N.; Eck, T.F.; Slutsker, I.; Tanré, D.; Buis, J.P.; Setzer, A.; Vermote, E.; Reagan, J.A.; Kaufman, Y.J.; Nakajima, T. Aeronet-A federated instrument network and data archive for aerosol characterization. Remote Sens. Environ. 1998, 66, 1-16. [CrossRef]

21. Yu, H.; Kaufman, Y.J.; Chin, M.; Feingold, G. A review of measurement-based assessments of the aerosol direct radiative effect and forcing. Atmos. Chem. Phys. 2006, 6, 613-666. [CrossRef]

22. Kong, S.; Ji, Y.; Lu, B.; Zhao, X.; Han, B.; Bai, Z. Similarities and differences in $\mathrm{PM}_{2.5}, \mathrm{PM}_{10}$ and tsp chemical profiles of fugitive dust sources in a coastal oilfield city in China. Aerosol Air Qual. Res. 2014, 14, 2017-2028. [CrossRef]

23. Eck, T.; Holben, B.; Dubovik, O.; Smirnov, A.; Goloub, P.; Chen, H.; Chatenet, B.; Gomes, L.; Zhang, X.Y.; Tsay, S.C. Columnar aerosol optical properties at aeronet sites in central Eastern Asia and aerosol transport to the tropical Mid-Pacific. J. Geophys. Res. Atmos. 2005, 110, 887-908. [CrossRef]

24. Ocko, I.B.; Ginoux, P.A. Comparing multiple model-derived aerosol optical properties to collocated ground-based and satellite measurements. Atmos. Chem. Phys. 2017, 17, 1-35. [CrossRef] 
25. Kalashnikova, O.V.; Mills, F.P.; Eldering, A.; Anderson, D. Application of satellite and ground-based data to investigate the uv radiative effects of australian aerosols. Remote Sens. Environ. 2007, 107, 65-80. [CrossRef]

26. Xia, X.; Li, Z.; Holben, B.; Wang, P.; Eck, T.; Chen, H.; Cribb, M.; Zhao, Y. Aerosol optical properties and radiative effects in the yangtze delta Region of China. J. Geophys. Res. Atmos. 2007, 112, 449-456. [CrossRef]

27. Liu, Y.; Huang, J.; Shi, G.; Takamura, T. Aerosol optical properties and radiative effect determined from sky-radiometer over loess plateau of Northwest China. Atmos. Chem. Phys. 2011, 11, 11455-11463. [CrossRef]

28. Che, H.; Xia, X.; Zhu, J.; Wang, H.; Wang, Y.; Sun, J.; Zhang, X.; Shi, G. Aerosol optical properties under the condition of heavy haze over an urban site of Beijing, China. Environ. Sci. Pollut. Res. 2015, 22, 1043-1053. [CrossRef] [PubMed]

29. Klingmüller, K.; Pozzer, A.; Metzger, S.; Stenchikov, G.L.; Lelieveld, J. Aerosol optical depth trend over the Middle East. Atmos. Chem. Phys. 2016, 16, 5063-5073. [CrossRef]

30. Wang, L.; Gong, W.; Xia, X.; Zhu, J.; Li, J.; Zhu, Z. Long-term observations of aerosol optical properties at Wuhan, an urban site in central China. Atmos. Environ. 2015, 101, 94-102. [CrossRef]

31. Levy, R.C.; Mattoo, S.; Munchak, L.A.; Remer, L.A. The collection 6 modis aerosol products over land and ocean. Atmos. Meas. Tech. 2013, 6, 2989-3034. [CrossRef]

32. Toledano, C.; Wiegner, M.; Groß, S.; Freudenthaler, V.; Gasteiger, J.; Müller, D.; Müller, T.; Schladitz, A.; Weinzierl, B.; Torres, B. Optical properties of aerosol mixtures derived from sun-sky radiometry during samum-2. Tellus Ser. B Chem. Phys. Meteorol. 2011, 63, 635-648. [CrossRef]

33. Che, H.; Zhang, X.; Chen, H.; Damiri, B.; Goloub, P.; Li, Z.; Zhang, X.; Wei, Y.; Zhou, H.; Dong, F. Instrument calibration and aerosol optical depth validation of the China aerosol remote sensing network. J. Geophys. Res. Atmos. 2009, 114, D03206. [CrossRef]

34. Dubovik, O.; King, M.D. A flexible inversion algorithm for retrieval of aerosol optical properties from sun and sky radiance measurements. J. Geophys. Res. Atmos. 2000, 105, 20673-20696. [CrossRef]

35. Dubovik, O.; Sinyuk, A.; Lapyonok, T.; Holben, B.N.; Mishchenko, M.; Yang, P.; Eck, T.F.; Volten, H.; Muñoz, O.; Veihelmann, B. Application of spheroid models to account for aerosol particle nonsphericity in remote sensing of desert dust. J. Geophys. Res. Atmos. 2006, 111, 34. [CrossRef]

36. Andrews, E.; Sheridan, P.J.; Fiebig, M.; Mccomiskey, A.; Ogren, J.A.; Arnott, P.; Covert, D.; Elleman, R.; Gasparini, R.; Collins, D. Comparison of methods for deriving aerosol asymmetry parameter. J. Geophys. Res. Atmos. 2006, 111, D05S04. [CrossRef]

37. Mayer, B.; Kylling, A. Technical note: The libradtran software package for radiative transfer calculations-Description and examples of use. Atmos. Chem. Phys. 2005, 5, 1855-1877. [CrossRef]

38. Kylling, A.; Stamnes, K.; Tsay, S.-C. A reliable and efficient two-stream algorithm for spherical radiative transfer: Documentation of accuracy in realistic layered media. J. Atmos. Chem. 1995, 21, 115-150. [CrossRef]

39. Stamnes, K.; Tsay, S.C.; Wiscombe, W.; Jayaweera, K. Numerically stable algorithm for discrete-ordinatemethod radiative transfer in multiple scattering and emitting layered media. Appl. Opt. 1988, 27, 2502-2509. [CrossRef] [PubMed]

40. Stamnes, K.; Tsay, S.-C.; Wiscombe, W.; Laszlo, I. DISORT, a General-Purpose Fortran Program for Discrete-Ordinate-Method Radiative Transfer in Scattering and Emitting Layered Media: Documentation of Methodology; Department of Physics and Engineering Physics, Stevens Institute of Technology: Hoboken, NJ, USA, 2000.

41. Lucht, W.; Roujean, J.L. Considerations in the parametric modeling of brdf and albedo from multiangular satellite sensor observations. Remote Sens. Rev. 2000, 18, 343-379. [CrossRef]

42. Moody, E.G.; King, M.D.; Platnick, S.; Schaaf, C.B.; Gao, F. Spatially complete global spectral surface albedos: Value-added datasets derived from terra modis land products. IEEE Trans. Geosci. Remote Sens. 2005, 43, 144-158. [CrossRef]

43. Bi, J.; Huang, J.; Hu, Z.; Holben, B.; Guo, Z. Investigating the aerosol optical and radiative characteristics of heavy haze episodes in Beijing during january of 2013. J. Geophys. Res. Atmos. 2014, 119, 9884-9900. [CrossRef]

44. Mateos, D.; Antón, M.; Toledano, C.; Cachorro, V.E.; Aladosarboledas, L.; Sorribas, M.; Costa, M.J.; Baldasano, J.M. Aerosol radiative effects in the ultraviolet, visible, and near-infrared spectral ranges using long-term aerosol data series over the iberian peninsula. Atmos. Chem. Phys. 2014, 14, 13497-13514. [CrossRef] 
45. Hsu, Y.K.; Holsen, T.M.; Hopke, P.K. Comparison of hybrid receptor models to locate pcb sources in Chicago. Atmos. Environ. 2003, 37, 545-562. [CrossRef]

46. Tao, M.; Chen, L.; Xiong, X.; Zhang, M.; Ma, P.; Tao, J.; Wang, Z. Formation process of the widespread extreme haze pollution over Northern China in January 2013: Implications for regional air quality and climate. Atmos. Environ. 2014, 98, 417-425. [CrossRef]

47. Zhang, M.; Ma, Y.; Gong, W.; Wang, L.; Xia, X.; Che, H.; Hu, B.; Liu, B. Aerosol radiative effect in uv, vis, nir, and sw spectra under haze and high-humidity urban conditions. Atmos. Environ. 2017, 166, 9-21. [CrossRef]

48. Che, H.; Xia, X.; Zhu, J.; Li, Z.; Dubovik, O.; Holben, B.; Goloub, P.; Chen, H.; Estelles, V.; Cuevasagulló, E. Column aerosol optical properties and aerosol radiative forcing during a serious haze-fog month over North China plain in 2013 based on ground-based sunphotometer measurements. Atmos. Chem. Phys. 2014, 14, 2125-2138. [CrossRef]

49. Qi, Y.; Ge, J.; Huang, J. Spatial and temporal distribution of modis and misr aerosol optical depth over Northern China and comparison with aeronet. Chin. Sci. Bull. 2013, 58, 2497-2506. [CrossRef]

50. Liu, Y.B.; Ju, W.M.; Chen, J.M.; Zhu, G.L.; Xing, B.L.; Zhu, J.F.; He, M.Z. Spatial and temporal variations of forest lai in China during 2000-2010. Chin. Sci. Bull. 2012, 57, 2846-2856. [CrossRef]

51. Yao, X.; Wang, Z.; Wang, H. Impact of urbanization and land-use change on surface climate in middle and lower reaches of the yangtze river, 1988-2008. Adv. Meteorol. 2015, 2015, 1-10. [CrossRef]

52. Liu, B.; Ma, Y.; Gong, W.; Zhang, M. Observations of aerosol color ratio and depolarization ratio over Wuhan. Atmos. Pollut. Res. 2017. [CrossRef]

53. Xia, X.A.; Chen, H.B.; Wang, P.C.; Zhang, W.X.; Goloub, P.; Chatenet, B.; Eck, T.F.; Holben, B.N. Variation of column-integrated aerosol properties in a Chinese urban region. J. Geophys. Res. Atmos. 2006, 111, 769-785. [CrossRef]

54. Li, C.; Mao, J.; Lau, K.-H.A.; Chen, J.-C.; Yuan, Z.; Liu, X.; Zhu, A.; Liu, G. Characteristics of distribution and seasonal variation of aerosol optical depth in Eastern China with modis products. Chin. Sci. Bull. 2003, 48, 2488-2495.

55. Zhang, M.; Gong, W.; Ma, Y.; Wang, L.; Chen, Z. Transmission and division of total optical depth method: A universal calibration method for sun photometric measurements. Geophys. Res. Lett. 2016, 43, 2974-2980. [CrossRef]

56. Gong, W.; Zhang, T.; Zhu, Z.; Ma, Y.; Ma, X.; Wang, W. Characteristics of $\mathrm{PM}_{1.0}, \mathrm{PM}_{2.5}$, and $\mathrm{PM}_{10}$, and their relation to black carbon in Wuhan, central China. Atmosphere 2015, 6, 1377-1387. [CrossRef]

57. Xia, X.; Che, H.; Zhu, J.; Chen, H.; Cong, Z.; Deng, X.; Fan, X.; Fu, Y.; Goloub, P.; Jiang, H. Ground-based remote sensing of aerosol climatology in China: Aerosol optical properties, direct radiative effect and its parameterization. Atmos. Environ. 2016, 124, 243-251. [CrossRef]

58. Mie, G. Beitrage zur optik truber medien, speziell kolloidaler metallosungen. Ann. Phys. 1908, 25, 377-445. [CrossRef]

59. Eldering, A.; Cass, G.R.; Moon, K.C. An air monitoring network using continuous particle size distribution monitors: Connecting pollutant properties to visibility via mie scattering calculations. Atmos. Environ. 1994, 28, 2733-2749. [CrossRef]

60. Wang, L.; Chen, Y.; Niu, Y.; Salazar, G.A.; Gong, W. Analysis of atmospheric turbidity in clear skies at Wuhan, central China. J. Earth Sci. 2017, 28, 1-10. [CrossRef]

61. Loeb, N.G.; Su, W. Direct aerosol radiative forcing uncertainty based on a radiative perturbation analysis. J. Clim. 2010, 23, 5288-5293. [CrossRef]

(C) 2017 by the authors. Licensee MDPI, Basel, Switzerland. This article is an open access article distributed under the terms and conditions of the Creative Commons Attribution (CC BY) license (http:/ / creativecommons.org/licenses/by/4.0/). 